\title{
An Improved Preventive Maintenance Scheduling for a Photovoltaic Plant under Environmental Constraints
}

\author{
Aisha Sa'ad ( $\nabla$ aisha.sa-ad@univ-lorraine.fr) \\ Universite de Lorraine \\ Aime Nyoungue \\ Universite de Lorraine \\ Zied Hajej \\ Universite de Lorraine
}

\section{Research Article}

Keywords: photovoltaic system, reliability, selective maintenance, preventive maintenance, optimization, availability, environmental constraint

Posted Date: June 4th, 2021

DOI: https://doi.org/10.21203/rs.3.rs-542572/v1

License: (c) (i) This work is licensed under a Creative Commons Attribution 4.0 International License. Read Full License 


\title{
An Improved Preventive Maintenance Scheduling for a Photovoltaic Plant under Environmental Constraints
}

\author{
Aisha Sa' ad ${ }^{1}$, Aime Nyoungue ${ }^{1}$, Zied Hajej $^{1}$ \\ ${ }^{1}$ Laboratoire de Genie Informatique, de Production et de Maintenance, University of Lorraine, \\ Metz, France \\ Aisha.sa-ad@univ-lorraine.fr \\ Aime.nyoungue@univ-lorraine.fr \\ Zied.hajej@univ-lorraine.fr
}

\begin{abstract}
To be able to supply PV power that satisfies customer demand at all times, there is need for the generating plant to be available at all time. However, with the increased age and usage of the components, the component's reliability reduces resulting to failure. These failures were due to a range of causes such as degradation and electrical wiring aging and cuts leading to a reduced performance efficiency and reliability. Therefore, to ameliorate the reliability of the system, a combined selective and preventive maintenance actions were planned by determining the best combination (optimal preventive maintenance intervals, optimal replaced components). In this work, an optimal preventive maintenance strategy with minimal repair was developed using iterative numerical technique for a photovoltaic (PV) plant with and without considering the influence of environmental condition on the system. An algorithm was developed on MATLAB to determine the optimal number of preventive maintenance actions that yields maximum availability by selecting the components to be maintained based on the reliability threshold without considering the environmental impact on the components. The environmental elements' criticality was introduced and the reliability reiterated based on the new technique. Finally, by maximizing the availability of the system, an optimal preventive maintenance for a finite horizon was established.
\end{abstract}

Keywords: photovoltaic system, reliability, selective maintenance, preventive maintenance, optimization, availability, environmental constraint.

\section{$1 \quad$ Introduction}

Nowadays, the conventional energy sector becomes a very challenging area due to their high environmental impact. This energy generation mode brings into question air pollution, causing an increase in the greenhouse effect that in turn causes global warming. This caused renewable energy sources to gain attention, thereby necessitating the provision of various alternative energy sources including photovoltaics, wind energy, concentrated solar power (CSP) amongst others. Solar energy is the most abundant renewable energy source and appeared to be one of the most exploited renewable energy sources especially for electricity generation globally [1], reaching approximately $227 \mathrm{GW}$ plant installations worldwide [2]. The increased growth rate of the PV exploitation increased the attention of investors, government organizations and other stakeholders for financial investment whose aim is to ensure that the PV systems reliably and cost-effectively generates energy. Failures of critical assets are sometimes catastrophic and result in extended downtime which are disadvantageous for the financial outcome of the investment, client satisfaction and safety. One of the Sustainable 
Development goals (SDGs) is affordable clean energy, which further emphasises the criticality of renewable energy and cleaner technologies [3].

Reliability, availability, and maintainability (RAM) assessment is usually implemented in order to ensure maximum availability of the photovoltaic energy production at all-times [4]. Reliability and maintainability are important in measuring the effectiveness of systems. The major difference between reliability and maintainability is that reliability is the probability that a failure will not occur in a particular time, while maintainability is the probability that required maintenance will be successfully accomplished within a given time period. Maintainability is a design characteristic that affects accuracy, ease, and time requirements of maintenance actions which may be measured by combining factors such as maintenance frequency, maintenance costs, repair times, and labour hours [5].

All systems, equipment and components' functionality tend to wane with usage and age. Preventive maintenance (PM) is often implemented to improve the overall system reliability and availability. PM scheduling plays a very important role in the successful, economical, and reliable operation of engineering systems. When maintenance actions are rarely performed especially imperfect maintenance, frequent system failures occur resulting in long downtime which affects the availability of the system as well as the financial benefit associated with it. However, when performed too often, it can cause material wastage and considerable increase in maintenance cost. Optimal scheduling becomes necessary in order to balance between the cost of maintenance and material usage as well as reducing downtime to maximize availability which are critical decision variables for any preventive maintenance policy.

In a system comprising of different subsystems and sub-components, it is important to establish a maintenance strategy to find the maintenance priority of components within available resources. Due to constrained resources, not all possible maintenance actions can be performed on a system [6], which makes it imperative to optimally select the component to be maintained. This work deals with optimal selective PM action and ensuring maximum availability, bearing in mind a reliability threshold as the key decision variable for the maintenance action. Environmental condition impact on the reliability was also assessed as an extension of the work.

Although the PV reliability notion was recognized about four decades ago [7], its significance over an entire PV generation system remains vague due to the complex nature of PV systems. Therefore, reliability analysis represents a decisive issue for the system planning. Majority of the existing literature focused on the reliability assessment of different subsystems, such as the inverter [8], PV module [9,10], and balance of systems (BOS) [11]. Much fewer literature discusses the reliability evaluation for entire PV system. Simplified, system-level models for PV system reliability using a Markov modelling concept was presented by [12]. Periodic PM schedule for the service life of a mechanical series system was optimized by [13] where they defined a formula to calculate the redundant life of the series and was used as the criterion for replacement selection.

PM action model was developed by [14] to maximize system availability during each interval by formulating a constant value used as an improvement factor. Their model was based on the assumption that the time interval for a component with least life in a series system to be considered the maintenance interval period. This however was considered uneconomical because of high maintenance cost and material wastage. Vaurio [15] explored the timedependent unavailability of sporadically tested aging components under different testing and 
repair policies. Age diagnostic based renewal strategy was determined by Legat et al. [16] for an optimal PM strategy defined over finite time horizon.

Vatn et al. [17] optimized the maintenance of energy production system taking into account safety and environment by minimizing production / maintenance costs. Further studies have treated both predictive and preventive maintenance using multi-objective optimization model to power distribution networks. Reliability and availability of PV system by means of general reliability analysis methods were studied by [18,19]. Fault tree method with an exponential probability distribution function was used to analyse the components of 7 largescale PV systems in [19], the method serves as a suitable tool for identifying the most critical components of PV systems and helps in identifying areas that planned maintenance should be focused on. Quantitative risk analysis technique was used by [18] on 20kW grid-connected PV system over a 25-year period to analyze the system and to assist in developing better maintenance strategies, and thus to realize maximum benefit of photovoltaic power.

Failure mode and effects (Critical) analysis (FME(C)A) was applied to a reliability centred maintenance (RCM) to conserve the reliability of a PV system by failure modes identification. The result obtained was used to calculate the risk priority number (RPN) of the system which served as the decision variable of the maintenance [20]. Different models and maintenance strategies were developed by many researchers $[13,14]$ in order to attain optimal preventive maintenance actions which are mostly cost minimization and selective preventive maintenance strategy. Very few literatures focus on availability based maintenance strategies and to the best of our knowledge, no one ever considered the influence of environmental condition on the reliability of the system.

The goal of this work is to propose a new PM strategy that maximises the availability of a PV system. We will find the optimal number of periodic preventive maintenance actions within a finite time horizon and then make a selective maintenance decision to choose the best components to be replaced during each action in order to guarantee maximum reliability. The proposed model will determine the components within the system to be maintained during a maintenance period. Additionally, the study explores the influence of environmental condition on the reliability of the system as the second part of the work. The originality of this work is to consider a combined preventive and selective maintenance strategy by determining the best combination of optimal number of preventive maintenance action as well as the best replaced components. Consequently, a perfect preventive maintenance action is considered if the all components are replaced during this action that restored the photovoltaic system to as good as new state otherwise an imperfect preventive is considered. On the other hand, an important originality is considered by studying the impact of the environmental factor on the combined preventive and selective maintenance strategy.

Thus the work is organised as follows: Section 2 explains the PV system, the components considered, assumptions made, notations applied and the concept of selective/preventive maintenance strategy. Section 3 discusses the availability and reliability modelling approaches within the study under nominal condition as well as environmental assessment condition. Section 4 provides details of an optimization algorithm to determine the optimal combination (number of PM actions, selected of components to replaced). Section 5 is the numerical example and result obtained while section 6 concludes the study. 


\subsection{PV system failure causes}

A typical photovoltaic plant is a complex system composed of different electronic devices particularly photovoltaic modules and inverters of which the reliability will be studied throughout this work. Generally, the photovoltaic modules are connected either in series, in parallel or a combination of both. When connected in series, it ameliorates the voltage while in parallel ameliorates the current. Different series are connected in series to improve the intensity to form the photovoltaic field. As the output of the photovoltaic field is a direct current, the series are connected via DC Wires to the inverters which are then used to convert the output to an alternative current (AC). The output of the inverters is transported via AC Wires to the load. Figure 1 is a simplified scheme of a PV Plant.

PV panels, AC and DC wires and inverter are considered to reduce complexity of the reliability computing in this work. As mentioned earlier, the objective of this work are to maximize the system availability and to explore the environmental influence on the reliability of the photovoltaic system. Thus, we have defined the major failures of each device and the environmental elements that influence those failures. The photovoltaic modules or panels are the most important devices of the photovoltaic system. They have various components such as photovoltaic cells, interconnectors, diode bypass, junction box, protective glass on both sides and ribbons. Their main failures are the components failures; Hotspot (an under-irradiated part of the panel behaves as a receiver which causes a heating of the zone), Delamination (separation of the bond between the plastics on the back and the glass on the front of the panel which allows air and moisture to creep inside), Discoloration and corrosion due to chemical reactions. Same failure causes considered for the DC and AC Wires; Cut and corrosion. Finally, the inverter doesn't have detailed failure causes. Tablel matches each failure with the weather elements influencing its failure cause.

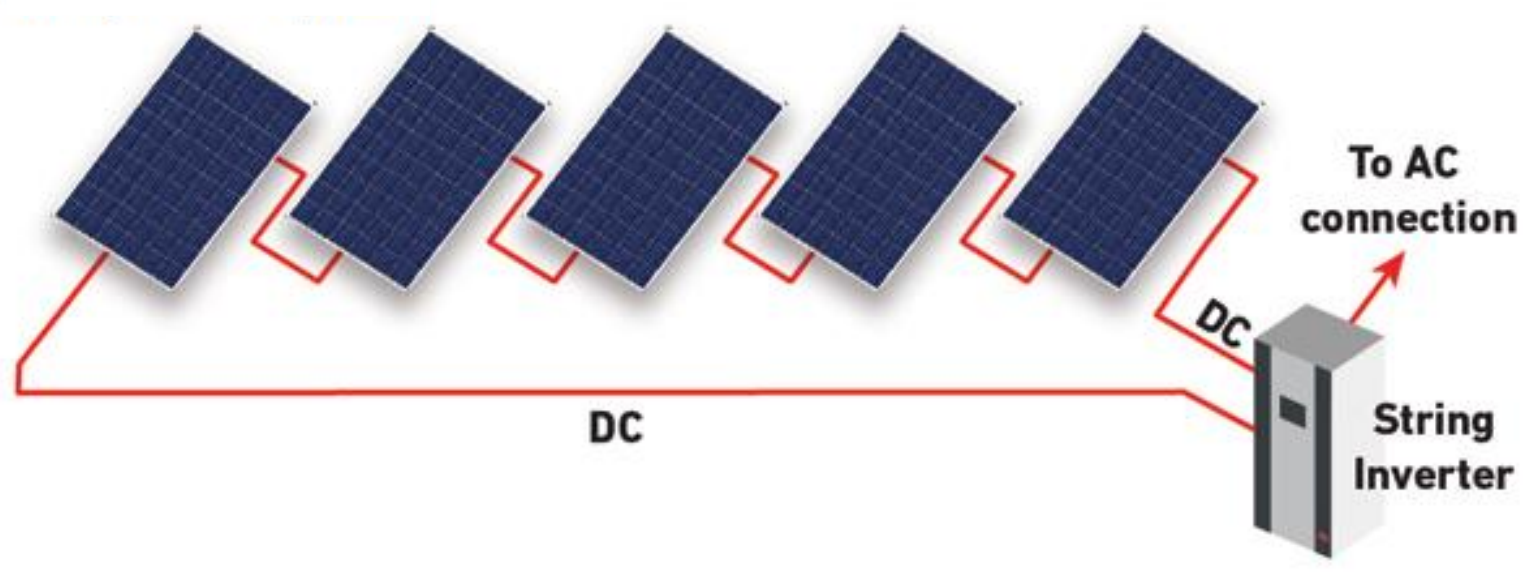

Fig 1: A PV field layout

An optimal preventive maintenance strategy with minimal repair was developed and applied to an electrical production system composed of several solar panels in a series structure. Indeed, in such a situation of failure of various photovoltaic system components, a minimal repair is applied characterized by a corrective maintenance action in order to resume back to operation 
of the photovoltaic system with the same failure rate it had before failure is called 'as bad as old' [29]. In order to reduce the probability of failure as well as the average number of failure of the photovoltaic system, a systematic periodic preventive maintenance was developed. In each preventive maintenance action, this work develops a priority selective maintenance strategy to choose and replace the most degraded components so as to guarantee maximal availability. At the same time, a minimal repair characterized by a palliative action to put it back into service by quickly adjusting or replacing certain elements, such as photovoltaic cells, interconnectors, diode bypass, junction box..., diodes or wires, without improving its reliability (that is, without reducing its failure rate).

We want to determine the optimal number of preventive maintenance actions that maximizes the photovoltaic system availability. More precisely, the maintenance strategy adopted consists of systematically replacing a certain number of the photovoltaic system components at different time units with different components replaced each time depending on the component's reliability. The failures that the global system can suffer are generally malfunctions, cable breaks, and poor power supply.

\section{TABLE I}

Failures and the type of environmental element(s) influencing the failure

\begin{tabular}{llllll}
\hline Component & Failure & $T$ & $\boldsymbol{I}$ & $\mathrm{Hu}$ & $\boldsymbol{P}$ \\
\hline Photovoltaic & Hotspots & & $\mathbf{x}$ & & \\
Panel & Junction box & $\mathbf{x}$ & & $\mathbf{x}$ & \\
& Broken glass & $\mathbf{x}$ & $\mathbf{x}$ & & $\mathbf{x}$ \\
& Diode bypass & & $\mathbf{x}$ & & \\
& Delamination & $\mathbf{x}$ & & $\mathbf{x}$ & \\
& Broken cells & $\mathbf{x}$ & & & $\mathbf{x}$ \\
& Welding ribbons & $\mathbf{x}$ & & $\mathbf{x}$ & \\
& Interconnections & $\mathbf{x}$ & & $\mathbf{x}$ & \\
& Discoloration & & $\mathbf{x}$ & & \\
& Corrosion & $\mathbf{x}$ & & $\mathbf{x}$ & \\
DC/AC & Cut or melt & $\mathbf{x}$ & & & \\
Wires & Corrosion & $\mathbf{x}$ & & $\mathbf{x}$ & \\
Inverter & Failure & $\mathbf{x}$ & & $\mathbf{x}$ & \\
\hline & & & & &
\end{tabular}

Where: T refers to Temperature, I to Irradiance, Hu to Humidity and P to Pressure

\subsection{Notations and assumptions}

\section{A: $\quad$ Notations used in the mathematical model}

A: $\quad$ Availability

T: $\quad$ Production horizon

$\mathrm{T}_{\text {maintenance: }}$ Total maintenance duration

$\mathrm{R}(\mathrm{t}): \quad$ System reliability at $\mathrm{t}$

$\mathrm{C}_{\mathrm{j}}$ : $\quad$ Criticality coefficient of failure of the system

$\mathrm{N}$ : $\quad$ Number of maintenance actions

$\mathrm{R}^{*}$ : $\quad$ Minimum required reliability threshold

$\mathrm{k}$ : $\quad$ Maintenance period 
$\mathrm{R}_{\text {equipment: }}$ Reliability function of equipment

$\mathrm{R}_{\text {cause: }} \quad$ Reliability function of cause of failure for a component

$R_{, j}(t)$ Reliability of the $j^{\text {th }}$ component under the effect of environmental condition

$\mathrm{R}_{\mathrm{o}, \mathrm{j}}(\mathrm{t})$ : Reliability of the $\mathrm{j}^{\text {th }}$ component under nominal condition

$\mathrm{C}_{\mathrm{o}, \mathrm{j}}$ : $\quad$ Criticality coefficient of $\mathrm{j}^{\text {th }}$ component

$\mathrm{a} / \mathrm{b}_{\text {cause: }} \quad$ Failure cause constant under chemical influence

$\mu_{p}: \quad$ Preventive maintenance time

$\mu_{c}: \quad$ Corrective maintenance time

$\varphi(N): \quad$ Number of Average failure rate

$\beta_{j}$ : $\quad$ Criticality coefficient vector for component $\mathrm{j}$

$\lambda_{j / i}: \quad$ Constant failure rate of components/subcomponents

$\mathrm{Z}_{\mathrm{i}}: \quad$ Vector of environmental conditions

$\mathrm{Z}^{\mathrm{EC}}$ : $\quad$ Environmental condition representation

\section{B: Assumptions}

1. The system and the components within are in a binary state, that is, they are either working or failed.

2 Minimal repair is performed as soon as a component fails during a mission.

3 After replacement, a component is "as good as new." When minimal repair is performed, it becomes " as bad as old."

$4 \quad$ All failures are assumed to be random and independent

5 For the electrical components' failure, the reliability is exponentially distributed with a constant failure rate while Weibull distribution was used for other types of failures.

6 The failure rate of the same components is the same.

7 For equipment having various causes, the reliability was assumed to be the product of the reliabilities of all the causes.

\subsection{Selective maintenance}

This section is aimed at establishing the optimal selective maintenance with high reliability level to ensure the next energy production periods run without discontinuity considering the obtained reliability estimation of the photovoltaic system under operating and environmental conditions. For this purpose, the photovoltaic is considered as a multicomponent system and whose components are only maintained in the predetermined optimal maintenance periods $N$ that was computed in the preventive maintenance strategy. At each selective maintenance period $k=1,2, \ldots, N^{*}$, the objective of priority selective maintenance is to select the right components $i=1,2, \ldots, N_{c}$ to be maintained, so that a required reliability level is guaranteed until the next shutdown.

Figure 2 shows a typical reliability system evolution of preventive maintenance. When the reliability of a system falls below a certain minimum threshold $\mathrm{R}^{*}$, maintenance is performed on the components depending on the required maintenance type. If for example as in figure 2, when maintenance is carried out at $\mathrm{T}$, some components only requires servicing and/or repairs, in that case, imperfect maintenance is carried out. This increases the system reliability by making it younger but not completely making it new. At 2T, the type of maintenance carried out is a perfect maintenance which occurs when all components are replaced. At this point, the system becomes completely As Good As New (AGAN). The failure 
rate however, decreases with increase in maintenance as seen in figure 3. As such, it is minimized when imperfect maintenance is performed and becomes nearly zero (except when manufacturing failure occurs) when a perfect maintenance is performed.



Figure 2: Evolution of the reliability of a system

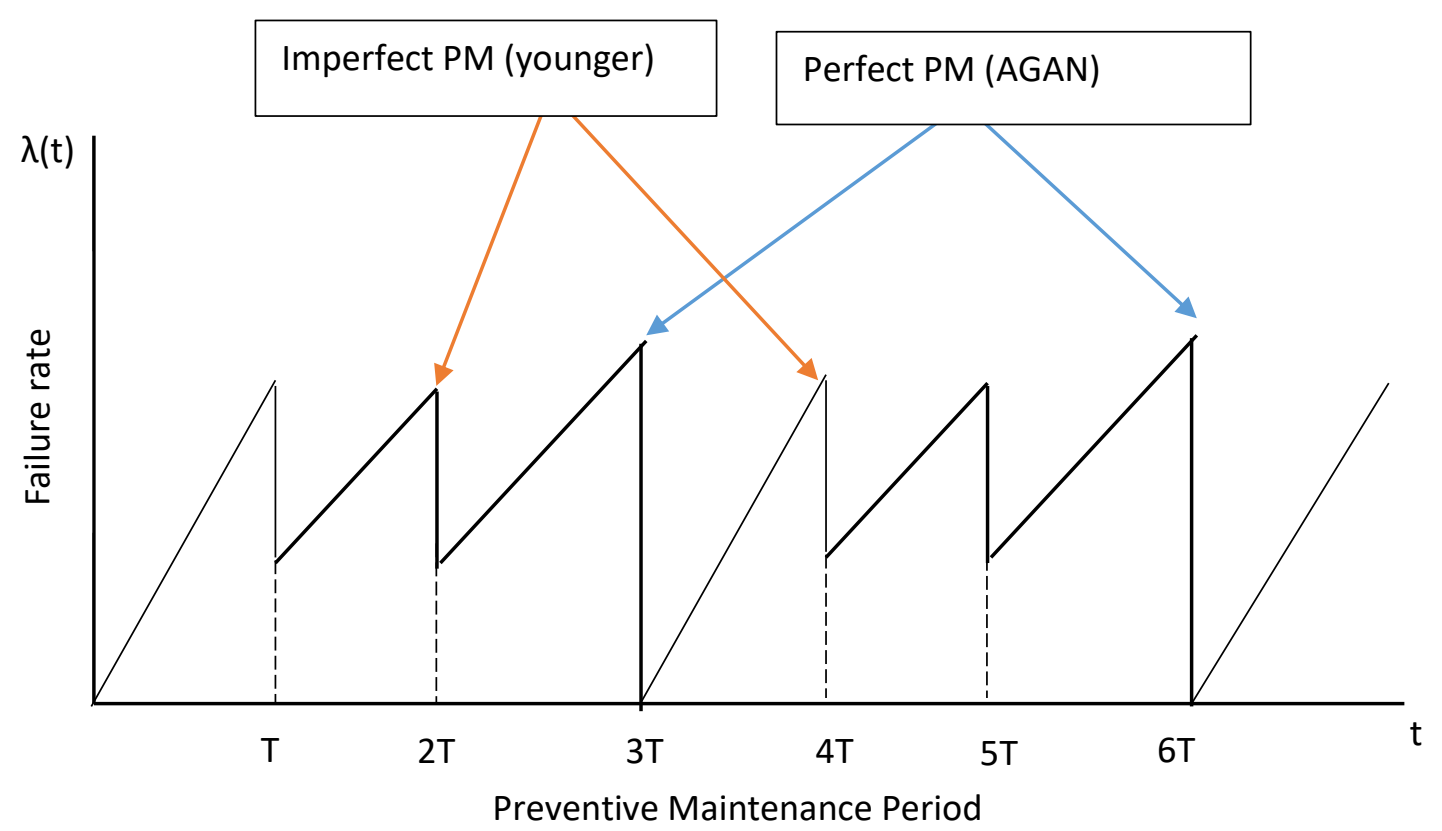

Figure 3: failure rate illustration during preventive maintenance actions 


\section{PROBLEM FORMULATION}

\subsection{Availability formulation}

The objective of this work is optimal scheduling of maintenance actions for a photovoltaic plant. For this purpose, the problem of the availability maximization constrained to the reliability threshold was considered. In this section, a mathematical model was developed to express the availability of photovoltaic system as a function of the decision variables: the optimal number of preventive maintenance actions $N^{*}$ and the component to be replaced if it is to be maintained based on reliability threshold. The availability of the system is expressed as follow:

$$
\begin{gathered}
A=\frac{T-T_{\text {maintenance }}}{T} \\
T_{\text {maintenance }}=\text { preventive maintenance duration } \\
+ \text { corrective maintenance duration }
\end{gathered}
$$

It was observed that the availability is inversely proportional to the maintenance duration therefore the problem is remodeled as:

$$
\text { Min } T_{\text {maintenance }}
$$

subject to

$$
R(t)>R^{*} \forall t
$$

The aim of this work is to maximize the availability of the system having in mind that the reliability of the photovoltaic system should be greater than a fixed minimum value called $\mathrm{R}^{*}$. Thus, the problem is formulated as follows:

Objective Function

$$
\operatorname{Max} A=\frac{T-T_{\text {maintenance }}}{T}
$$

Where

$$
T_{\text {maintenance }}(N)=\underbrace{\sum_{k=1}^{N} \sum_{i=1}^{N C}\left[\mu_{P_{i}} \times m_{i}(k)\right]}_{\text {preventive maintenance duration }}+\underbrace{\mu c \times \varphi(\mathrm{N})}_{\text {corrective maintenance duration }}
$$

Subject to

$$
\begin{gathered}
R_{P V}\left(k \cdot T, Z^{E C}\right) \geq R^{*} \\
m_{i}(k)=\left\{\begin{array}{lr}
1 & \text { ifth component is to be replaced during period } k \\
0 & \text { otherwise }
\end{array}\right.
\end{gathered}
$$

The average number of failure is expressed as follows

$$
\varphi(\mathrm{N})=\sum_{k=0}^{N-1}\left[\int_{k . T}^{(k+1) \cdot T} \lambda_{P V k}(t) d t\right]+\int_{N . T}^{H . \Delta t} \lambda_{P V k}(t) d t
$$


where:

$$
\lambda_{P V, k}(t)=\frac{-\frac{d R_{P V, k}(t)}{d t}}{R_{P V}(t)}
$$

Here, the preventive maintenance time $\left(\mu_{P_{i}}\right)$ can be defined as the sum of the duration of the following jobs:

i. Access time $\left(t_{1}\right)$ : This is the time required to gain access to and identify the failed component to be maintained by disassembling the system.

ii. Inspection time $\left(\mathrm{t}_{2}\right)$ : The time required to determine and diagnose the cause of failure.

iii. Replacement (or repair) time $\left(\mathrm{t}_{3}\right)$ : Once the component has been identified and inspected, this is the actual time of carrying out the main PM activity of either repair or replacement depending on the manager's decision.

iv. Assembling time ( $\left.\mathrm{t}_{4}\right)$ : This is the last stage consisting of verification, alignment and assembling the dismantled system to get it back up into operation.

Furthermore, the Corrective Maintenance time $(\mu c)$ in addition to the above mentioned time incurs additional time since the failure occurs unexpectedly [14]. The additional times are stated as follows:

i. Supply delay time: the time delay in obtaining necessary spare parts or components.

ii. Maintenance delay time: the time spent waiting for the maintenance personnel, resources and facilities to be in place.

\subsection{Photovoltaic reliability estimation}

\subsubsection{Reliability probability estimation}

Let $\mathrm{T}$ be a random variable referring to the time to failure of an equipment and $\mathrm{P}$ the probability of its failure. Having in mind the assumptions made above, the reliability of the equipment at $t$ is defined as the probability that the system will not fail before or at that instant. $\mathrm{R}$ is then the probability that $\mathrm{T}$ is greater than $\mathrm{t}$. This is explicated as follows:

$$
\begin{aligned}
& R(t)=P(T>t) \\
& R(t)=P\left(T_{1}>t_{1}, T_{2}>t_{2}, \ldots, T_{n}>t_{n}\right)
\end{aligned}
$$

The PV system is complex and contains a large number of sub-assemblies that may be connected in series, parallel or even a combination of both. When the sub-assemblies are connected in series, the overall system will be interrupted in case of failure of one sub-assembly. However, all sub-assemblies must fail in order to interrupt the overall system in the parallel connected system. For components associated in series, the reliability of the group is assumed to be the product of each component reliability as shown in (8):

$$
R(t)=R_{1}(t) \cdot R_{2}(t) \ldots R_{n}(t)=\prod_{i=1}^{n} R_{i}(t)
$$


For equipment composed of different components associated in series, the unreliability function $\mathrm{Q}$ is used to define the reliability of the group. The unreliability of the equipment is the products of each component unreliability [22]:

$$
\begin{gathered}
Q(t)=1-R(t)=1-P(T>t) \\
Q(t)=Q_{1}(t) \cdot Q_{2}(t) \ldots Q_{n}(t)=\prod_{i=1}^{n} Q_{i}(t) \\
Q(t)=\left(1-R_{1}(t)\right) \cdot\left(1-R_{2}(t)\right) \ldots\left(1-R_{n}(t)\right) \\
R(t)=1-\prod_{i=1}^{n}\left(1-R_{i}(t)\right) \\
R(t)=1-\prod_{i=1}^{n}\left(1-P_{i}\left(T_{i}>t_{i}\right)\right)
\end{gathered}
$$

The reliability of the equipment having various failure causes is assumed to be the product of the reliability functions established for each failure cause. Therefore,

$$
R(t)=R_{\text {cause } 1}(t) \cdot R_{\text {cause } 2}(t) \ldots R_{\text {cause } n}(t)
$$

Equation 17 is summed into 18

$$
R(t)=\prod_{i=1}^{n} R_{\text {cause } i}(t)
$$

\subsubsection{Photovoltaic plant reliability:}

- System Reliability:

As mentioned earlier, a system is composed of photovoltaic field, Dc Wires, inverters and AC Wires associated in Series. Thus, the reliability of the whole system is expressed as:

$$
\begin{gathered}
R_{\text {system }}(t)=\prod_{i=1}^{4} R_{\text {component }, i}(t)^{n_{\text {component }, i}} \\
R_{\text {system }}(t)=R_{P V \text { field }}(t) \cdot R_{D C \text { Wire }}(t)^{n_{D C \text { Wires }}} \cdot R_{\text {Inverters }}(t)^{n_{\text {Inverters }}} \cdot R_{A C \text { Wires }}(t)^{n_{A C \text { Wires }}}
\end{gathered}
$$

- Photovoltaic Field Reliability:

The photovoltaic field is composed of $n_{\text {series }}$ number of photovoltaic components associated in series. Its reliability has then this form:

$$
R_{P V \text { field }}(t)=1-\prod_{i=1}^{n_{\text {series }}}\left(1-R_{\text {serie }, i}(t)\right)
$$

As the series are identical, their reliability functions are also identical. Thus the field reliability is equal to:

$$
R_{P V \text { field }}(t)=1-\left(1-R_{\text {serie }, i}(t)\right)^{n_{\text {series }}}
$$

- Photovoltaic Series Reliability: 
A Photovoltaic Series consists on $n_{\text {panels }}$ panels associated in series has the following form:

$$
\begin{aligned}
& R_{\text {serie }, i}(t)=\prod_{j=1}^{m} R_{\text {panel }, j}(t) \\
& R_{\text {serie }, i}(t)=\left(R_{\text {panel }}(t)\right)^{n_{\text {panels }}}
\end{aligned}
$$

- Photovoltaic Panel Reliability:

The reliability function of the photovoltaic Panel is expressed as follow:

$$
\begin{gathered}
R_{\text {panel }}(t)=R_{\text {panel components }}(t) \cdot R_{\text {causes }}(t) \\
R_{\text {panel components }}(t)= \\
R_{\text {junction box }}(t) \cdot R_{\text {glass }}(t) \cdot R_{\text {bypass Diode }}(t) \cdot R_{\text {cells }}(t) \cdot R_{\text {ribons }}(t) \cdot R_{\text {interconnectors }}(t)
\end{gathered}
$$

$$
R_{\text {causes }}(t)=R_{\text {delamination }}(t) \cdot R_{\text {hotspot }}(t) \cdot R_{\text {discoloration }}(t) \cdot R_{\text {corrosion }}(t)
$$

- DC/AC wires_Reliability:

The DC Wires and the AC Wires reliability functions are of the same form, as such they are treated in a similar way:

$$
R_{\text {wire }}(t)=R_{\text {cut }}(t) \cdot R_{\text {corrosion }}(t)
$$

- Inverter Reliability:

The inverter is a complex and expensive component of a photovoltaic system. The main causes of failure in inverters are mainly design problems, manufacturing defects and poor management practices [23] even though the effect of temperature and humidity can affect the functionality of the inverter. Thus, low inverter reliability contributes to an unreliable system and a loss of confidence in the renewable technology. The reliability function described by an exponential distribution and will be explicitly expressed in the next subsection.

\subsection{Explicit Reliability functions}

More explicitly, the reliability of components is often characterized by failure rate $\lambda$ and is expressed as in the equation thus:

$$
R=e^{-\lambda t}
$$

It was established based on [24], that the reliability functions of the different components depend only on time and independent of atmospheric conditions; hence for each component, the explicit reliability functions are given as follows:

\section{PV Panels}

For the PV Panels, the components and the causes for failure $R_{\text {junction box }}(t), R_{\text {glass }}(t)$, $R_{\text {bypass Diode }}(t), R_{\text {cells }}(t), R_{\text {ribons }}(t), R_{\text {hotspot }}(t), R_{\text {delamination }}(t)$, and $R_{\text {interconnectors }}(t)$ have the same form given as: 


$$
R_{\text {equiment } / \text { cause }}(t)=e^{-\lambda_{\text {equiment } / \text { cause }} \cdot t}
$$

Thus, the reliability of the panel components is expressed by:

$$
R_{\text {panel components }}(t)=e^{-\left(\lambda_{\text {junction box }}+\lambda_{\text {bypass Diode }}+\lambda_{\text {cells }}+\lambda_{\text {ribons }}+\lambda_{\text {interconnectors }}\right) \cdot t}
$$

The reliability functions related to the discoloration and corrosion failures $R_{\text {discoloration }}(t)$, $R_{\text {corrosion }}(t)$ are expressed as follows:

$$
R_{\text {cause }}(t)=e^{-b_{\text {cause }} . t+a_{\text {cause }}}
$$

Thus, $\mathrm{R}_{\text {cause }}$ is expressed by:

$$
R_{\text {discoloration/corrosion }}(t)=e^{-\left(b_{\text {discoloration }}+b_{\text {corrosion }}\right) \cdot t+a_{\text {discoloration }}+a_{\text {corrosion }}}
$$

Those failures are due to chemical reactions and this is the reason for using different probability distribution.

$$
\begin{aligned}
R_{\text {panel }}(t) & =e^{-\left(\lambda_{\text {junction box }}+\lambda_{\text {bypass Diode }}+\lambda_{\text {cells }}+\lambda_{\text {ribons }}+\lambda_{\text {interconnectors }}\right) \cdot t} \\
& \cdot e^{-\left(b_{\text {discoloration }}+b_{\text {corrosion }}\right) \cdot t+a_{\text {discoloration }}+a_{\text {corrosion }}}
\end{aligned}
$$

\section{DC/AC wires:}

The Wires have two failure causes; cut and corrosion. For each cause, the reliability function has a different form:

$$
\begin{aligned}
& R_{\text {cut }}(t)=e^{-\lambda_{\text {cut }} t} \\
& R_{\text {corrosion }}(t)=1-C_{\text {corrosion }} \cdot t^{a_{\text {corrosion }}}
\end{aligned}
$$

The reliability of the AC and DC wires is then:

$$
R_{\text {wire }}(t)=\left(1-C_{\text {corrosion-wire }} \cdot t^{a_{\text {corrosion-wire }}}\right) \cdot e^{-\lambda_{\text {cut-wire }} \cdot t}
$$

Inverter:

The reliability function of the inverter is described by an exponential distribution:

$$
R_{\text {inverter }}(t)=e^{-\lambda_{\text {inverter }}}
$$

Thus the reliability expression of one photovoltaic system is expressed by:

$$
R_{p v}(t)=R_{\text {panel }}(t) \cdot R_{A C \text {-wire }}(t) \cdot R_{D C \text {-wire }}(t) \cdot R_{\text {inverter }}(t)
$$

Therefore,

$$
\begin{aligned}
& R_{p v}(t)=e^{-\left(\lambda_{\text {junction box }}+\lambda_{\text {bypass Diode }}+\lambda_{\text {cells }}+\lambda_{\text {ribons }}+\lambda_{\text {interconnectors }}\right) \cdot t} \\
& \cdot\left(e^{-\left(b_{\text {discoloration }}+b_{\text {corrosion }}\right) \cdot t+a_{\text {discoloration }}+a_{\text {corrosion }}}\right) \\
& \cdot\left(\left(1-C_{\text {corrosion }-D C} \cdot t^{\left.a_{\text {corrosion }-D C}\right)} \cdot e^{-\lambda_{\text {cut }-D C} \cdot t}\right)\right. \\
& \cdot\left(\left(1-C_{\text {corrosion-AC }} \cdot t^{\left.a_{\text {corrosion }-A C}\right)}\right) \cdot e^{-\lambda_{\text {cut }-A C} \cdot t}\right) \cdot e^{-\lambda_{\text {inverter }} \cdot t}
\end{aligned}
$$


Consequently, the reliability of photovoltaic power plant is given by:

$$
\begin{aligned}
& R_{\text {pvplant }}(t)=(1-(1- \\
& \left.\left.\left(R_{\text {panel }}(t)\right)^{n_{\text {panels }}}\right)^{n_{\text {series }}}\right) \cdot R_{D C \text { Wire }}(t)^{n_{D C \text { Wires }}} \cdot R_{\text {Inverters }}(t)^{n_{\text {Inverters }}} \cdot R_{A C \text { Wires }}(t)^{n_{A C} \text { Wires }}
\end{aligned}
$$

Subsequently,

$$
\begin{aligned}
R_{\text {pvplant }}(t)= \\
\left(1-\left(1-\left(e^{-\left(\lambda_{\text {junction box }}+\lambda_{\text {junction box }}+\lambda_{\text {cells }}+\lambda_{\text {ribons }}+\lambda_{\text {interconnectors }}\right) \cdot t}\right.\right.\right. \\
\cdot e^{\left.\left.\left.-\left(b_{\text {discoloration }}+b_{\text {corrosion }}\right) \cdot t+a_{\text {discoloration }}+a_{\text {corrosion }}\right)^{n_{\text {panels }}}\right)^{n_{\text {series }}}\right)} \\
\cdot\left(\left(1-C_{\text {corrosion-DC }} \cdot t^{\left.\left.a_{\text {corrosion }-D C}\right) \cdot e^{-\lambda_{\text {cut }-D C} \cdot t}\right)^{n_{D C \text { Wires }}}}\right.\right. \\
\cdot\left(\left(1-C_{\text {corrosion-AC }} \cdot t^{\left.a_{\text {corrosion }-A c}\right)} \cdot e^{-\lambda_{\text {cut }-A C \cdot t}}\right)^{n_{A C \text { Wires }}}\right. \\
\cdot\left(e^{-\lambda_{\text {inverter }} \cdot t}\right)^{n_{\text {inverter }}}
\end{aligned}
$$

Moreover, if a maintenance action is applied at the instant $k . T$ with $(k: 1, \ldots, N)$, the reliability of the Photovoltaic_plant is expressed:

$$
\begin{aligned}
& R_{\text {pvplant }}(k \cdot T)=R_{\text {panel }}(k . T)^{\left(1-m_{i}(k)\right)} \cdot R_{\text {ACwire }}(k . T)^{\left(1-m_{i}(k)\right)} \cdot R_{\text {DCwire }}(k \cdot T)^{\left(1-m_{i}(k)\right)} . \\
& R_{\text {inverter }}(k . T)^{\left(1-m_{i}(k)\right)} \\
& R_{p v}(k . T)=e^{-\left(\lambda_{\text {junction box }}+\lambda_{\text {bypass Diode }}+\lambda_{\text {cells }}+\lambda_{\text {interconnectors }}\right) \cdot k \cdot T \cdot\left(1-m_{i}(k)\right)} \\
& \cdot\left(e^{-\left(b_{\text {discoloration }}+b_{\text {corrosion }}\right) \cdot k \cdot T+a_{\text {discoloration }}+a_{\text {corrosion }}}\right)^{\left(1-m_{i}(k)\right)} \\
& \cdot\left(1-C_{\text {corrosion-DC }}(k \cdot T)^{a_{\text {corrosion-DC }}}\right)^{\left(1-m_{i}(k)\right)} \cdot e^{-\lambda_{\text {cut }-D C} \cdot k \cdot T \cdot\left(1-m_{i}(k)\right)}
\end{aligned}
$$

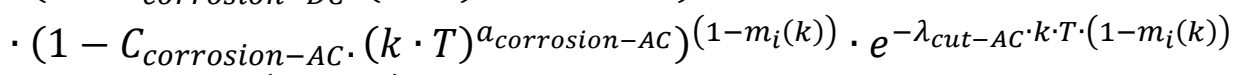

$$
\begin{aligned}
& \cdot e^{-\lambda_{\text {inverter }} \cdot k \cdot T \cdot\left(1-m_{i}(k)\right)}
\end{aligned}
$$

And Consequently the reliability of photovoltaic power plant:

$$
\begin{gathered}
R_{\text {pvplant }}(k \cdot T)=\left(1-\left(1-\left(R_{\text {panel }}(k \cdot T)^{\left(1-m_{i}(k)\right)}\right)^{n_{\text {panels }}}\right)^{n_{\text {series }}}\right) . \\
\left(R_{\text {DCwire }}(k \cdot T)^{\left(1-m_{i}(k)\right)}\right)^{n_{D C \text { Wires }}} \cdot\left(R_{\text {inverter }}(k \cdot T)^{\left(1-m_{i}(k)\right)}\right)^{n_{\text {Inverters }}} \cdot\left(R_{\text {ACwire }}(k \cdot T)^{\left(1-m_{i}(k)\right)}\right)^{n_{\text {ACWires }}}
\end{gathered}
$$

\subsection{Photovoltaic Plant Reliability under Environmental Condition Influence}

In this section, an in-depth study of the reliability estimation of photovoltaic components as a function of environmental conditions using a parametric relationship between environmental and risk factors was carried out. Each climatic factor $z_{i}$ is associated with a weighting coefficient $\beta_{i, j}$ that quantifies the influence of climatic factors on the photovoltaic system. A multiplicative regression model for survival data (Cox) regression model was used to establish the relationship between the reliability function established under nominal climatic conditions 
$\left(R_{0, j}(t)\right)$ and the function $C_{j}(Z)$ of $j$ climatic conditions. To integrate the environmental impact on the reliability function, a criticality coefficient $(C)$ for each failure was defined [25]. The coefficient is the product of the frequency (F), the Detectability (D) and the severity (S) of each failure.

$$
C=F \times D \times S
$$

Based on the indication of the environmental elements that stimulates each failure type as shown in Table I, different values of the criticality coefficient were defined based on the weather data. The environmental data was explored by assigning a value between 0 and 5 to each element according to its real value. The mathematical expression of the criticality coefficient as a function of the weather elements was established as in (46) and shown in figure 4. The idea is to amplify the degeneration of reliability if the environmental conditions were more critical and recompense if otherwise.

$$
C_{j}(Z)=e^{\beta_{j} Z}=e^{\beta_{0, j}+\sum \beta_{i, j} Z_{i}}
$$

Where:

$\beta_{j}=\left(\beta_{0, j}, \beta_{1, j}, \beta_{2, j}, \beta_{3, j}, \beta_{4, j}\right)$ is the vector of parameters of $C_{j}(Z)$

Equation (46) is reconstructed as (47) where the criticality coefficient $c_{j}(Z)$ is defined as:

$$
c_{j}(Z)=\frac{C_{j}(Z)}{C_{0, j}}=\frac{e^{\sum \beta_{i, j} Z_{i}}}{C_{0, j}}
$$

where $C_{0, j}$ is considered the constant of criticality for each component.

$$
\begin{aligned}
& Z_{1}: \text { Temperature } \\
& \begin{array}{rrrrrr}
<-2 & <3.4 & <8.8 & <14.2 & <19.6 \\
0 & 1 & 2 & 3 & 4 & 5
\end{array} \\
& Z_{2}: \text { Irradiance } \\
& \begin{array}{cccccc}
<120 & <186 & <252 & <318 & <384 & \\
0 & 1 & 2 & 3 & 4 & 5
\end{array} \\
& Z_{3}: \text { Humidity } \\
& \begin{array}{rrrrrr}
<42 & <45.6 & <49.2 & <52.8 & <56.4 \\
0 & 1 & 2 & 3 & 4 & 5
\end{array} \\
& Z_{4}: \text { Pression } \\
& <808<810.4<812.8<815.2<817.6 \\
& \begin{array}{llllll}
0 & 1 & 2 & 3 & 4 & 5
\end{array}
\end{aligned}
$$

Figure 4: Criticality coefficient of the weather elements 
The criticality factor $(\mathrm{Cj})$ was integrated into the reliability function equation yielding equation (48). $R_{j}(t)$ denotes the reliability function of the $i^{t h}$ component/cause depending only on time while $R_{0, j}(t)$ is the reliability for nominal environmental conditions. Given that $R_{j}(t, Z)$ must imperatively decrease over time, we opted for the integration of the previous value of this function. So the following expression was developed for each reliability function related to each failure/component:

$$
R_{j}(t, Z)=R_{j}\left(t-1, Z_{t-1}\right)-\left(R_{0, j}(t-1)-R_{0, j}(t)\right) * c_{j}
$$

Where:

$Z_{t-1}$ : is the vector of environmental elements corresponding to the time instant $(\mathrm{t}-1)$.

And $H_{j}=R_{j}(t, Z)-R_{j}\left(t-1, Z_{t-1}\right)$

Thus: $\quad\left\{\begin{array}{l}c_{j}<1: H_{j}<R_{0, j}(t)-R_{0, j}(t-1) \\ c_{j}=1: H_{j}=R_{0, j}(t)-R_{0, j}(t-1) \\ c_{j}>1: H_{j}>R_{0, j}(t)-R_{0, j}(t-1)\end{array}\right.$

The reliability of the plant at $\mathrm{t}$ under condition $\mathrm{Z}$ becomes

$$
\begin{aligned}
& R_{\text {pvplant }}(t, Z)=R_{\text {pvplant }}\left(t-1, Z_{t-1}\right)-\left(\left(\left(1-\left(1-\left(R_{\text {panel }}(t-1)\right)^{n_{\text {panels }}}\right)^{n_{\text {series }}}\right) \cdot R_{D C \text { Wire }}(t-\right.\right. \\
& \left.1)^{n_{D C \text { Wires }}} \cdot R_{\text {Inverters }}(t-1)^{n_{\text {Inverters }}} \cdot R_{A C \text { Wires }}(t-1)^{n_{\text {AC Wires }}}\right)-((1-(1- \\
& \left.\left.\left.\left.\left(R_{\text {panel }}(t)\right)^{n_{\text {panels }}}\right)^{n_{\text {series }}}\right) \cdot R_{D C \text { Wire }}(t)^{n_{D C \text { Wires }}} \cdot R_{\text {Inverters }}(t)^{n_{\text {Inverters }}} \cdot R_{A C \text { Wires }}(t)^{n_{A C \text { Wires }}}\right) \times \frac{e^{\sum_{i, k} \cdot z_{i}}}{C_{0, k}}\right)
\end{aligned}
$$

More explicitely it becomes

$$
R_{\text {pvplant }}(t, Z)=R_{\text {pvplant }}\left(t-1, Z_{t-1}\right)-
$$

$\left(\left(1-\left(1-\left(e^{-\left(\lambda_{\text {junction box }}+\lambda_{\text {cells }}+\lambda_{\text {ribons }}+\lambda_{\text {interconnectors }}\right) \cdot(t-1)}\right.\right.\right.\right.$.

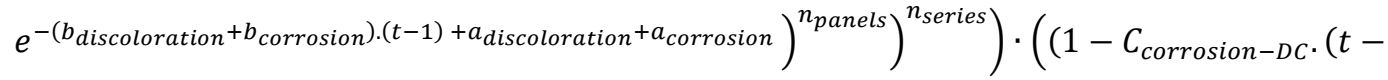

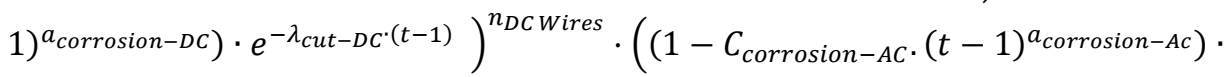

$\left.e^{-\lambda_{\text {cut }-A C \cdot(t-1)}}\right)^{n_{A C \text { Wires }}} \cdot\left(e^{-\lambda_{\text {inverter }} \cdot(t-1)}\right)^{n_{\text {inverter }}}-(1-(1-$

$\left(e^{-\left(\lambda_{\text {junction box }}+\lambda_{\text {cells }}+\lambda_{\text {ribons }}+\lambda_{\text {interconnectors }}\right) \cdot t}\right.$.

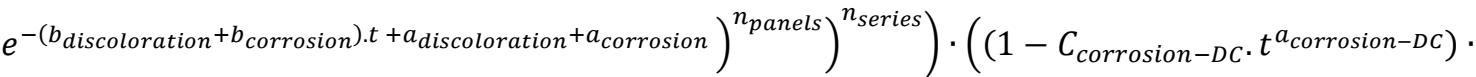

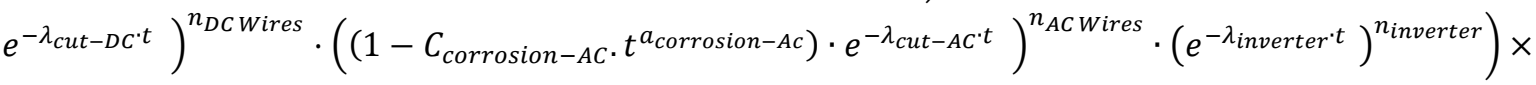

$\frac{e^{\sum \beta_{i, k} \cdot Z_{i}}}{C_{0, k}}$

If a maintenance action is applied at the instant $k . T$ with $(k: 1, \ldots, N)$, the reliability of the Photovoltaic plant is expressed: 


$$
\begin{aligned}
& R_{\text {pvplant }}(k \cdot T, Z)= \\
& \left(\begin{array}{c}
\left(1-\left(1-\left(R_{\text {panel }}(k \cdot T, Z)^{\left(1-m_{i}(k)\right)}\right)^{n_{\text {panels }}}\right)^{n_{\text {series }}}\right) \cdot\left(R_{D C w i r e}(k \cdot T, Z)^{\left(1-m_{i}(k)\right)}\right)^{n_{D C \text { Wires }}} \\
\cdot\left(R_{\text {inverter }}(k \cdot T, Z)^{\left(1-m_{i}(k)\right)}\right)^{n_{\text {Inverters }}} \cdot\left(R_{\text {ACwire }}(k \cdot T, Z)^{\left(1-m_{i}(k)\right)}\right)^{n_{A C \text { Wires }}}
\end{array}\right) \times \\
& \frac{e^{\sum \beta_{i, k^{\prime}} Z_{i}}}{C_{0, k}}
\end{aligned}
$$

\section{Optimization Algorithm}

In order to apply an algorithm to problem, a series of steps have to be clearly defined. There are $\mathrm{N}$ number of maintenance action planned for the maintenance action. The objectives of the work are to determine the optimal number of maintenance actions to be carried out in order to achieve maximum availability while selecting the components to be maintained during each maintenance period depending on the component reliability at the time of the maintenance and to explore the influence of environmental condition on the reliability of the PV system. furthermore, there is no constraint on to the number of components to be maintained during each maintenance period. This is because some components life cycle and degradation factors are lower than others. An overview of the algorithm is shown in the flow chart in figure 5.

At the beginning of the horizon, all components are new and are assumed to have highest reliability. The maintenance scheduling is planned such that a selective maintenance on the components is carried out at the time of the preventive maintenance action. A vector representation showing he sequence of the maintenance action is a finite integer of string $\mathrm{m}$. Each element of $\mathrm{m}$ is one of the number of maintenance actions available. We start with $\mathrm{m}_{1}$ and calculate the reliability of the components to determine if the verification condition (reliability threshold) is met. Once an element in the solution string is selected for the first maintenance, the next element becomes the next action plan for the next maintenance plan. It is possible to find two identical strings of solution during the planning horizon; the vector is therefore constructed in a way that strikes out all duplicates of the string so that maintenance is carried out on each component once during a maintenance action period.

With the solution string constructed, the number of preventive maintenance action $(\mathrm{N})$ was set to $\mathrm{N}_{\max }$ and the threshold of reliability. the algorithm was set in such a way that for each $\mathrm{N}$ $\left(1: N_{\max }\right)$ selected, the maintenance time is evaluated using equation (6). The total maintenance time takes care of both the planned preventive and corrective maintenance time. The availability estimation as in equation 5 was subsequently followed. The availability achieved was stored and used as the threshold for the next availability estimation, and if the value is less than the previous value, the previous value remains the intended availability until a greater value is obtained, in other words, it stores only the maximum availability of the system. 


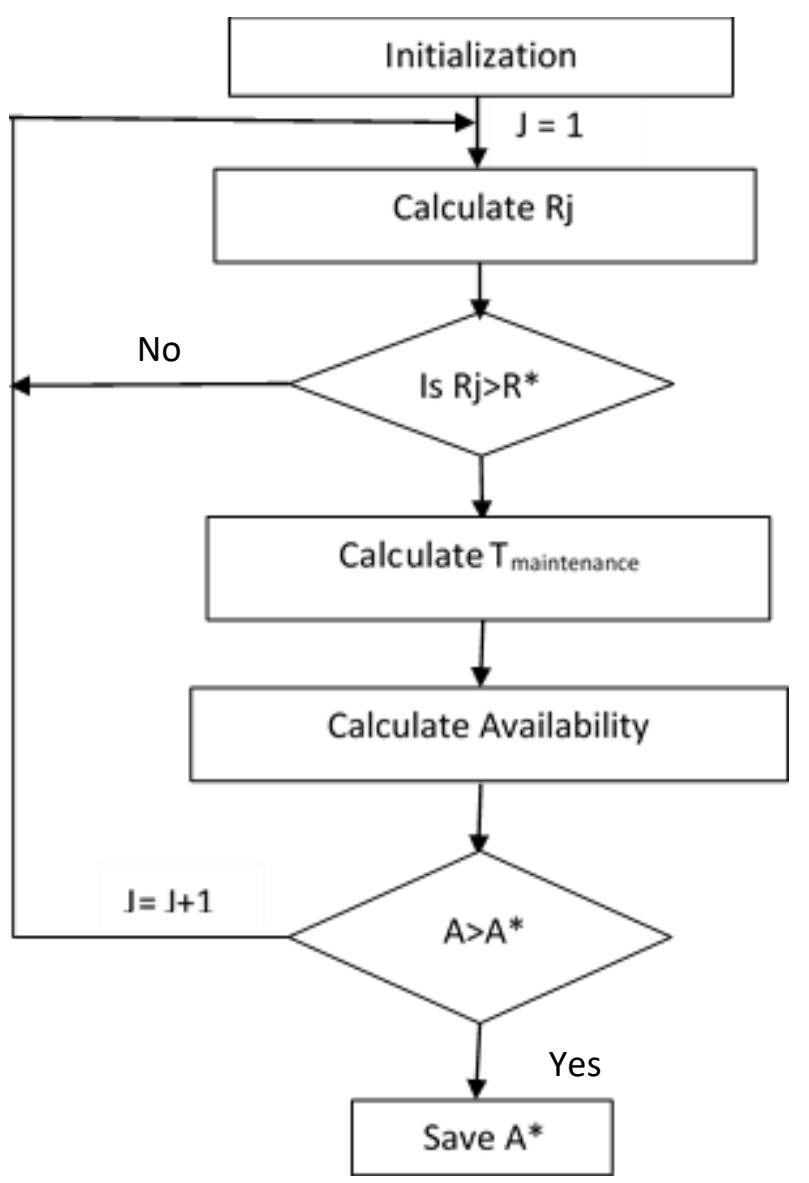

Figure 5: Algorithm flow chart

\section{Numerical Example}

Following the numerical optimization procedure based on the algorithm we developed for a finite number of maintenance actions, we propose the following numerical example whose values are arbitrarily chosen. The constant failure rates of the PV system components and subcomponents are tabulated in table 2. A PV system consisting of 3 PV modules connected in series, the output is connected to 2 inverters via DC cables. The inverter output is transmitted to the load via $2 \mathrm{AC}$ cables as well. The reparation rate for each component and the constant corrective maintenance time is also tabulated in table 3. Considering the environmental condition influencing the components/subcomponents, the criticality coefficient data is given in appendix 1 while the corresponding represented values were shown in Figure 4. The environmental condition parameters chosen for this purpose are 3,4,3,4 for temperature, humidity, irradiance and pressure respectively according to figure 4 and the chosen time horizon is 1000 units of time. Using this information, the system availability was determined under two scenarios mentioned as:

Scenario 1: System under nominal condition

Scenario 2: System under environmental condition assessment 
Table 2: Component/subcomponent constant failure rate

\begin{tabular}{|ll|}
\hline Failure mode & Constant Failure rate $\left(\mathrm{hr}^{-1}\right)$ \\
Hot spot & $7.13 \times 10^{-7}$ \\
Diode bypass & $5.85 \times 10^{-7}$ \\
Junction box & $7.87 \times 10^{-7}$ \\
Delamination & $5.44 \times 10^{-7}$ \\
Glass case (broken) & $5.44 \times 10^{-7}$ \\
Cell & $7.13 \times 10^{-6}$ \\
Soldering tape & $4.84 \times 10^{-6}$ \\
Interconnection box & $4.68 \times 10^{-6}$ \\
b-Discoloration & $1.36 \times 10^{-20}$ \\
a-Discoloration & $3.08 \times 10^{-20}$ \\
b-Corrosion & $1.61 \times 10^{-21}$ \\
a- Corrosion & $3.08 \times 10^{-20}$ \\
DC cable & $4.83 \times 10^{-8}$ \\
DC cable Corrosion coefficient & $1.68 \times 10^{-7}$ \\
AC cable & $1.30 \times 10^{-8}$ \\
AC cable Corrosion coefficient & $8.82 \times 10^{-8}$ \\
Inverter & $9.51 \times 10^{-6}$ \\
\hline
\end{tabular}

Table 3: PV system components' repair rate

\begin{tabular}{|c|c|c|}
\hline Component & PM time (unit) & \multirow{2}{*}{ CM (unit) } \\
\hline PV panel & 0.3 & \\
\hline DC wire & 0.2 & \\
\hline AC wire & 0.2 & \\
\hline Inverter & 0.3 & \\
\hline
\end{tabular}

\subsection{Results and Discussion}

After successful iteration of the algorithm, and varying the number of maintenance actions to obtain the optimal that yields maximum availability for both scenarios, it was observed as in Figure 6 under nominal condition, the system availability is maximum when three (3) maintenance action are performed. Figure 7 explains the availability of scenario 2 where the environmental elements' influence was taken into account. We noticed that only two (2) maintenance actions yielded the least down time. In figure 8, it is clear that the system is more available under the nominal condition even with the increased number of maintenance with scenario 2 having $99.1 \%$ under 10 maintenance actions, $98.7 \%$ at 15 and $98.2 \%$ at 20 . The corresponding values are $99.56 \%, 99.47$ and $99.37 \%$ for scenario 1 respectively. Large number was chosen in order to determine to ascertain that the value was the global maximum and not the local maximum. Considering the effect of the environment on the availability, the effect is more visible on the reliability than on the availability. 


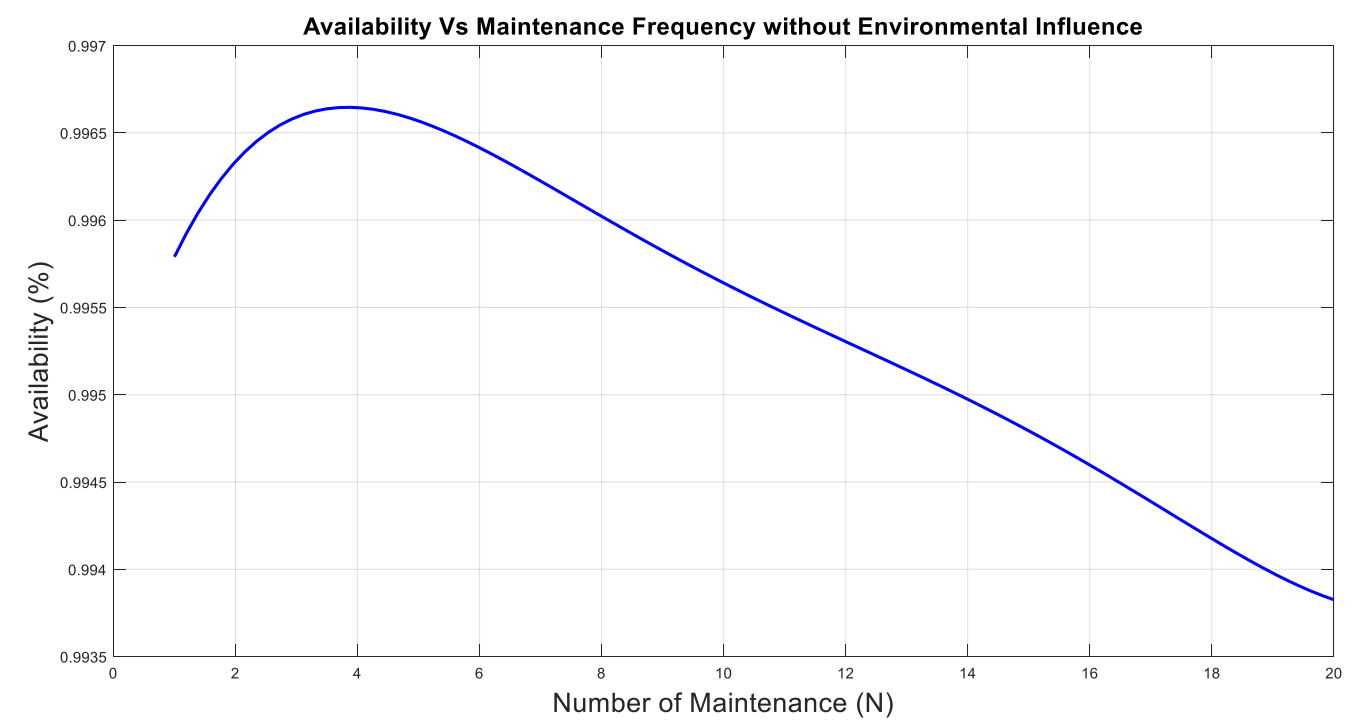

Figure 6: Availability for the system under the nominal environmental condition

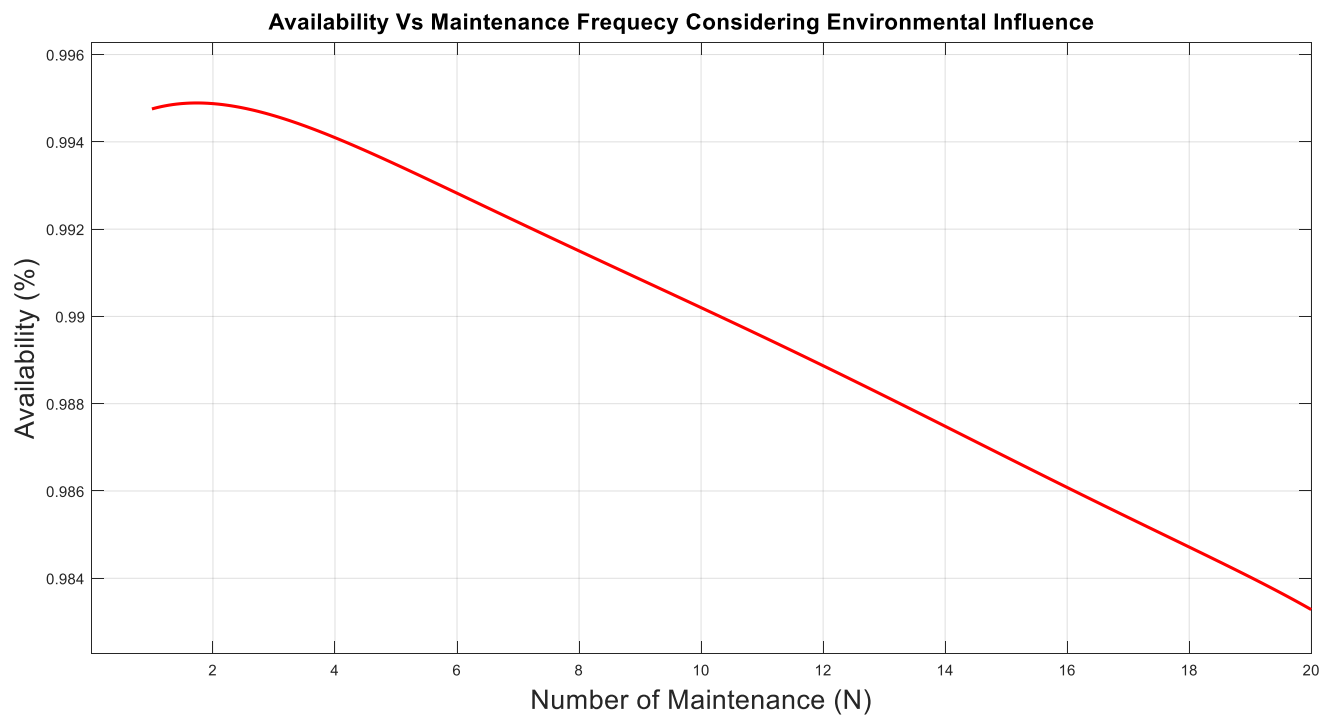

Figure 7: Availability for the system under the influence of the environmental condition 




Figure 8: Availability for the system comparing the 2 scenarios.

During each maintenance action, since it is assumed that components undergo perfect maintenance, they make the system almost as good as new if all the components are replaced which makes it highly reliable. Having the maximum number of maintenance that yields the availability, we can obtain the length between the maintenance missions as $1000 / \mathrm{N}^{*}$ representing 333 units for scenario1 and 500 units for scenario 2. In tables 4 and 5 the selected components to be replaced during each maintenance action are shown.

Table 4: Replaced components during the PM action in scenario 1 when $\mathrm{N}^{*}=3$

\begin{tabular}{|c|c|c|c|c|c|}
\hline Period (units) & $\begin{array}{c}\text { Reliability } \\
(\%)\end{array}$ & PV panel & AC wire & DC wire & Inverter \\
\hline 333 & 96.08 & $\mathrm{x}$ & $\mathrm{x}$ & - & - \\
\hline 666 & 99.36 & - & - & $\mathrm{x}$ & $\mathrm{x}$ \\
\hline 1000 & 99.99 & $\mathrm{x}$ & $\mathrm{x}$ & $\mathrm{x}$ & $\mathrm{x}$ \\
\hline
\end{tabular}

During the first action as in table 4, PV panel and AC wire were maintained making the system reliability to be $98.74 \%$ and $85.32 \%$ while the other 2 components were maintained. Whenever a component undergoes maintenance, it has a lower probability of failure. Hence, increasing the system reliability value is achieved for the next mission. At the last stream, a perfect maintenance was carried out by replacing all components and making the system "As Good As New". In table 5, only PV panel and inverter were maintained during the maintenance break with the system having $89.38 \%$ reliability with a total component replacement at the end of the horizon.

Table 5: Replaced components during the PM action in scenario 2 when $\mathrm{N} *=2$

\begin{tabular}{|c|c|c|c|c|c|}
\hline Period (units) & $\begin{array}{c}\text { Reliability } \\
(\%)\end{array}$ & PV panel & AC wire & DC wire & Inverter \\
\hline 500 & 89.38 & $\mathrm{x}$ & - & - & $\mathrm{x}$ \\
\hline 1000 & 99.99 & $\mathrm{x}$ & $\mathrm{x}$ & $\mathrm{x}$ & $\mathrm{x}$ \\
\hline
\end{tabular}




\subsection{Sensitivity analysis}

To validate the algorithm, we decided to test it with different values of the corrective maintenance time of 10 and 20 and the reparation time to be $0.2,0.1,0.15$ and 0.25 for the PV panel, DC and AC wires and the inverter respectively and criticality coefficient of 3, 4, 4, 1 for temperature, humidity, irradiance and pressure, the results are tabulated in tables 6 and 7 . From table 6 , the optimal number of missions are 5 for scenario 1 and 2 for scenario 2 . For scenario 2 , the optimal number remained the same as the initial condition but there is a slight variation in the availability from $99.50 \%$ to $99.75 \%$ under the same criticality condition for the system with decreased amount of CM and increased PM time. In table 7, both the CM and PM time were increased but the availability change is insignificant compared to the initial value of $99.50 \%$

Table 6: Result for CM time $=10$

\begin{tabular}{|l|l|l|}
\hline & Scenario 1 & Scenario 2 \\
\hline $\mathrm{N}^{*}$ & 5 & 2 \\
\hline $\mathrm{A}^{*}(\%)$ & 99.83 & 99.75 \\
\hline $\mathrm{R}(\%)$ & 97.25 & 70.57 \\
\hline
\end{tabular}

Table 7: Result for CM time $=20$

\begin{tabular}{|l|l|l|}
\hline & Scenario 1 & Scenario 2 \\
\hline$N^{*}$ & 4 & 4 \\
\hline$A^{*}(\%)$ & 99.64 & 99.51 \\
\hline$R(\%)$ & 96.58 & 72.72 \\
\hline
\end{tabular}

The reliabilities are seen to be decreasing from $97.25 \%$ to $96.58 \%$ under scenario 1 . This is because of the slight change in the optimal periodicity from 5 to 4 and increase in scenario 2 from $70.57 \%$ to $72.72 \%$ because it has shorter periodicity. To further explore the influence of the environmental condition, 4 different vectors were arbitrary built from fig 4 and tabulated in table 8 . The results tabulated in table 9 were used to compare to the results obtained in tables 6 and 7.

Table 8: Vector strings for environmental assessment

\begin{tabular}{cc}
\hline Vector & $\begin{array}{c}\text { Parameters } \\
{[\mathrm{T}, \mathrm{H}, \mathrm{I}, \mathrm{P}]}\end{array}$ \\
\hline 1 & {$[4,2,5,1]$} \\
2 & {$[2,4,5,5]$} \\
3 & {$[3,2,2,5]$} \\
4 & {$[2,3,3,5]$} \\
\hline
\end{tabular}

Table 9: Environmental influence with $\mathrm{cm}=10$ and $\mathrm{cm}=20$ for vectors 1 and 2

\begin{tabular}{|c|c|c|c|}
\hline Vector & Availability (\%) & \multicolumn{2}{|c|}{ Reliability (\%) } \\
\hline & & $\mathrm{CM}=10$ & $\mathrm{CM}=20$ \\
\hline 1 & 99.58 & 78.84 & 79.93 \\
\hline 2 & 99.62 & 26.70 & 27.50 \\
\hline 3 & 99.51 & 35.10 & 36.30 \\
\hline 4 & 99.48 & 13.60 & 14.10 \\
\hline
\end{tabular}

It is clear from table 9 that temperature plays the most significant role on the PV system. Therefore, when temperature is low, the reliability is seen to be affected drastically thereby 
making the system reliability ridiculously low while the pressure coefficient affects the reliability minimally. This can however, be attributed to the fact that temperature affects most of the components as seen in table 1. From table 9, the vector string V1 having temperature to 4 , humidity 2, Irradiance 5 and pressure 1 has the highest reliability of $78.84 \%$ when $\mathrm{CM}=10$ and $79.93 \%$ when $\mathrm{CM}=20$ with $99.58 \%$. In V2, temperature was decreased while humidity was increased and other parameters at maximum, the reliability was found to be $26.7 \%$ and $27.50 \%$ for CM 10 and 20 respectively. increasing temperature, reducing both humidity and irradiance while keeping the pressure constant as in V3 increased the reliability from $26.7 \%$ to $35.1 \%$ when CM10 and $27.5 \%$ to $36.3 \%$ when CM20. Lastly in V4, extremely low reliability is experienced with the vector parameters despite increasing the humidity and irradiance.

\section{Conclusion}

This paper presented an algorithm for selective preventive maintenance by considering the reliability threshold. The reliability of each component was calculated at the end of each mission and the components to be replaced were pre-determined. The availability of the system was determined for each scenario under each maintenance action so as to determine the optimal number of maintenance actions that ensures availability. The system reliabilities were also calculated considering the optimal number of maintenance while carrying out selective maintenance on the components. For both scenarios, 2 components were maintained during each action. Temperature, humidity, atmospheric pressure and solar irradiance are found to aggrevate failures in the photovoltaic system. their influence was considered in order to understand the magnitude of the effect on the system availability as well as the reliability. It was observed from the simulation result that the system needed to be maintained more frequently in scenario 2 resulting into ample downtime as compared with the system in scenario 1 condition.

The maintenance time was varied for the components as well as the environmental condition. From the analysis, temperature proved to be highly influential on the system. when the temperature coefficient is high as in V1, it yielded high reliability of $78.84 \%$ and $79.93 \%$ while in V4, it only yielded $13.60 \%$ and $14.10 \%$ respectively even when other parameters are sufficiently good. This high temperature improves the system reliability within the threshold. Therefore, the influence an environment has on the PV system was explored and the relationship with the maintenance time was established. It was evident that the environmental condition affects the reliability of the system significantly but has minimal effect on the availability. 


\section{DECLARATIONS}

\section{Ethical Approval}

Not applicable

\section{Consent to Participate}

Not applicable

\section{Consent to Publish}

Not applicable

\section{Authors Contribution}

The methodology of the work was developed by Zied Hajej and Aime Nyoungue while the algorithm / software development was done by Aisha Saad and Aime Nyoungue. Aisha Saad, Zied Hajej and Aime Nyoungue prepared the original draft preparation and it was validated by Zied Hajej and Aime Nyoungue. All authors have read and agreed to the submission of the manuscript

\section{Funding/ Competing Interest}

We certify that we have no affiliations with involvement in any organization or entity with any financial and/or non-financial interest in the research presented in this manuscript.

\section{Data Availability}

All data generated or analysed during this study are included in this published article.

\section{REFERENCES}

[1] García FP, Pedregal DJ, Roberts C (2010) Time series methods applied to failure prediction and detection. Reliab Eng Syst Saf 95(6):698-703.

[2] Kalogirou, S. (Ed.). (2017). McEvoy's Handbook of Photovoltaics: Fundamentals and Applications. Academic Press.

[3] Zied H., Rezg N., and Bouzoubaa M. (2017). An Integrated Maintenance Strategy for a Power Generation System under Failure Rate Variation, $6^{\text {th }}$ International Conference on Renewable Energy Research and Applications, San Diego, CA, USA, pp 5-8

[4] B.S. DHILLON, (1999). CHAPTER 3 - Maintainability Measures, Functions, and Models, Engineering Maintainability, Gulf Professional Publishing, Pages 32-49, https://doi.org/10.1016/B978-088415257-6/50003-X.

[5] Baschel, S.; Koubli, E.; Roy, J.; Gottschalg, R. (2018) Impact of Component Reliability on Large Scale Photovoltaic Systems' Performance. Energies 2018, 11, 1579.

[6] Pandey M., Zuo M.J., and Moghaddass R. (2015) Selective maintenance scheduling over a finite planning horizon, journal of risk and reliability, pp 1-16. DOI: 10.1177/1748006X15598914

[7] Stember LH, Huss WR, Bridgman MS(1982). A methodology for photovoltaic system reliability and economic analysis. IEEE Trans Rel; R-31(3):296-303. 
[8] Alonso, R.; Roman, E.; Sanz, A.; Santos, V.E.M.; Ibanez, P.(2012). Analysis of InverterVoltage Influence on Distributed MPPT Architecture Performance. IEEE Trans. Ind. Electron., 59, 3900-3907.

[9] Wohlgemuth, J.H.; Cunningham, D.W.; Monus, P.; Miller, J.; Nguyen, A. (2006). Long Term Reliability of Photovoltaic Modules. In Proceedings of the 2006 IEEE 4th World Conference on Photovoltaic Energy Conference, Waikoloa, HI, USA, 7-12 May 2006; Volume 2, pp. 2050-2053.

[10] Dhere, N.G.; Shiradkar, N.; Schneller, E.; Gade, V. (2013). The reliability of bypass diodes in PV modules. Proc. SPIE 2013, 8825.

[11] Cristaldi, L.; Khalil, M.; Faifer, M.; Soulatiantork, P.(2015). Markov process reliability model for photovoltaic module encapsulation failures. In Proceedings of the 2015 International Conference on Renewable Energy Research and Applications (ICRERA), Palermo, Italy, 22-25 November 2015; pp. 203-208.

[12] Dhople SV, Davoudi A, Chapman PL, Domi'nguez-Garci'a AD.(2010). In: Integrating photovoltaic inverter reliability into energy yield estimation with markov models. Control and modeling for power electronics (COMPEL), $12^{\text {th }}$ IEEE workshop pp. 1-5.

[13] Tsai Y, Wang K and Teng H.(2001). Optimizing preventive maintenance for mechanical components using genetic algorithms. Reliability Eng Syst Safe; 74(1): 89-97.

[14] Tsai Y, Wang K and Tsai L. (2004) A study of availability centered preventive maintenance for multi-component systems. Reliability Engng Syst Safe; 84(3): 261-270.

[15] Vaurio JK.(1997). On time-dependent availability and maintenance optimization of standby units under various maintenance policies. Reliability Engng Syst Safety;56/1:79_ 90 .

[16] Legat V, Zaludora AH, Cervenka V, Jurca V. (1996). Contribution to optimization of preventive replacement. Reliab Engng Syst Safety;51/3:259-66.

[17] Vatn, J., Hokstad, P., \& Bodsberg, L. (1996). An overall model for maintenance optimization. Reliability Engineering \& System Safety, 51(3), 241-257.

[18] Li, S. (2012). Condition-Dependent Risk Assessment of Large-Scale Grid-Tied Photovoltaic Power Systems. Masters' thesis report.

[19] Ahadi, A., Ghadimi, N., \& Mirabbasi, D. (2014). Reliability assessment for components of large scale photovoltaic systems. Journal of Power Sources, 264, 211-219.

[20] Colli, A. (2015). Failure mode and effect analysis for photovoltaic systems. Renew. Sustain. Energy Rev. 50, pp 804-809, https://doi.org/10.1016/j.rser.2015.05.056.

[21] Gertsbakh, I. Reliability Theory: With Applications to Preventive Maintenance, 1st ed.; Springer: Berlin, Germany, 2005; 219p.

[22] Shenoy, P. S., Kim, K. A., Johnson, B. B., \& Krein, P. T. (2013). Differential power processing for increased energy production and reliability of photovoltaic systems. IEEE Transactions on Power Electronics, 28(6), 2968-2979.

[23] A. Realini, (2003). Mean time before failure of photovoltaic modules final report, Final report BBW 99.0579, pp 49.

[24] Al-Rawi NA, Al-Kaisi MM, Asfer D. (1994). Reliability of photovoltaic modules II. Interconnections and bypass diodes effects. Solar Energy Materials and Solar Cells 1994;31(4):469-480.

[25] Benazzouz, A., Barhdadi, A., Fabrizio, B., \& Verdilio, D. (2016). Development of an Advanced Preventive Maintenance Plan for Grid-connected High Concentration Photovoltaic Power Plant. African Review of PHYSICS, 11, 81-87. 
Appendix 1

\begin{tabular}{|c|c|c|c|c|c|c|c|c|c|c|c|c|c|}
\hline & $\begin{array}{l}\text { Hot } \\
\text { spot }\end{array}$ & $\begin{array}{l}\text { Junctio } \\
\text { n box }\end{array}$ & $\begin{array}{l}\text { Glass } \\
\text { case }\end{array}$ & $\begin{array}{l}\text { Diode } \\
\text { bypass }\end{array}$ & $\begin{array}{c}\text { Delaminatio } \\
\mathbf{n}\end{array}$ & Cell & $\begin{array}{l}\text { Solderin } \\
\text { g tape }\end{array}$ & $\begin{array}{l}\text { Interconnecti } \\
\text { on box }\end{array}$ & $\begin{array}{c}\text { Discoloratio } \\
\mathbf{n}\end{array}$ & $\begin{array}{c}\text { Corrosio } \\
\mathrm{n}\end{array}$ & Cut & $\begin{array}{c}\text { Corrosio } \\
\text { n cable }\end{array}$ & $\begin{array}{c}\text { Inverte } \\
\mathrm{r}\end{array}$ \\
\hline Constant & 3.993 & 2.907 & 1.336 & 3.521 & 1.783 & 1.517 & 1.207 & 1.741 & 3.463 & 2.703 & 1.692 & 1.591 & 1.874 \\
\hline $\begin{array}{l}\text { Temperatur } \\
\mathrm{e}\end{array}$ & 0 & 0.141 & 0.461 & 0 & 0.228 & 0.293 & 0.438 & 0.213 & 0 & 0.153 & 0.365 & 0.133 & 0.395 \\
\hline Irradiance & 0.369 & 0 & 0 & 0.361 & 0 & 0 & 0 & 0 & 0.128 & 0.206 & 0 & 0 & 0 \\
\hline Humidity & 0 & 0.102 & 0 & 0 & 0.319 & 0 & 0.080 & 0.408 & 0.076 & 0 & 0 & 0.338 & 0.179 \\
\hline \multirow[t]{2}{*}{ Pressure } & 0 & 0 & 0 & 0 & 0 & 0.170 & 0 & 0 & 0 & 0 & 0 & 0 & 0 \\
\hline & 20.415 & 39.100 & 18.584 & 12.997 & 35.743 & 20.516 & 19.154 & 45.093 & 60.161 & 46.679 & 18.440 & 22.952 & 38.384 \\
\hline
\end{tabular}



Figures

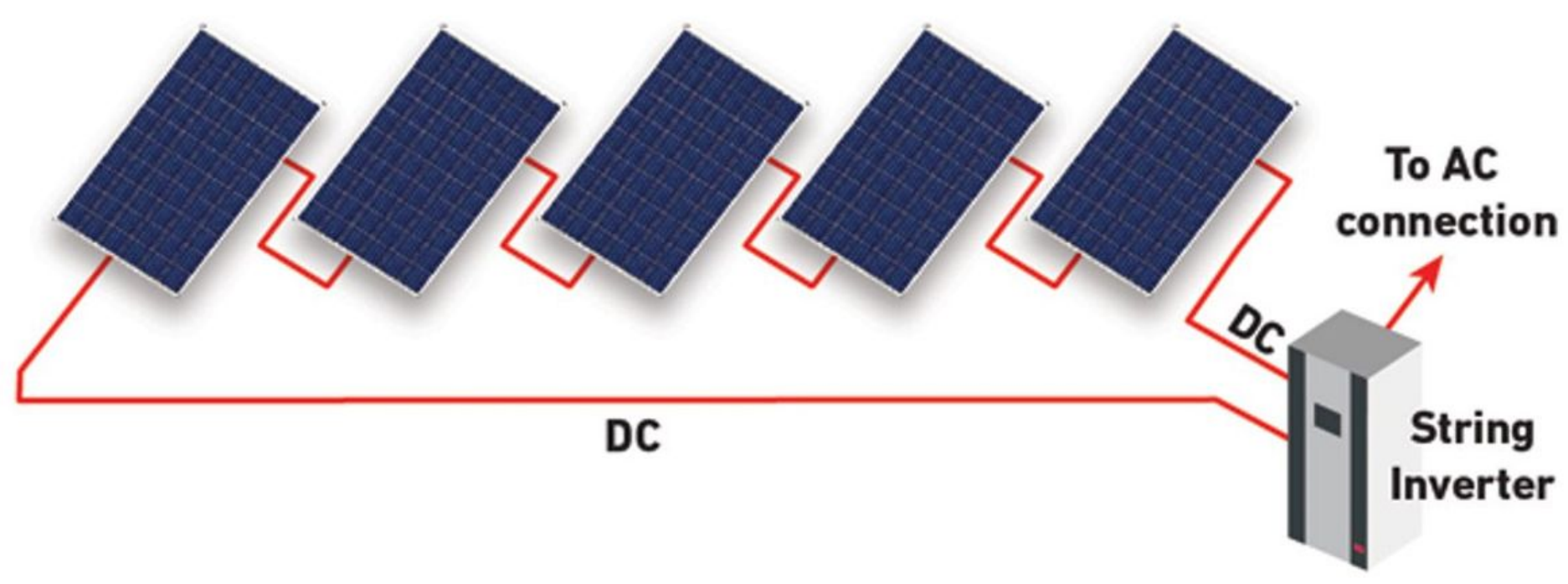

Figure 1

A PV field layout 


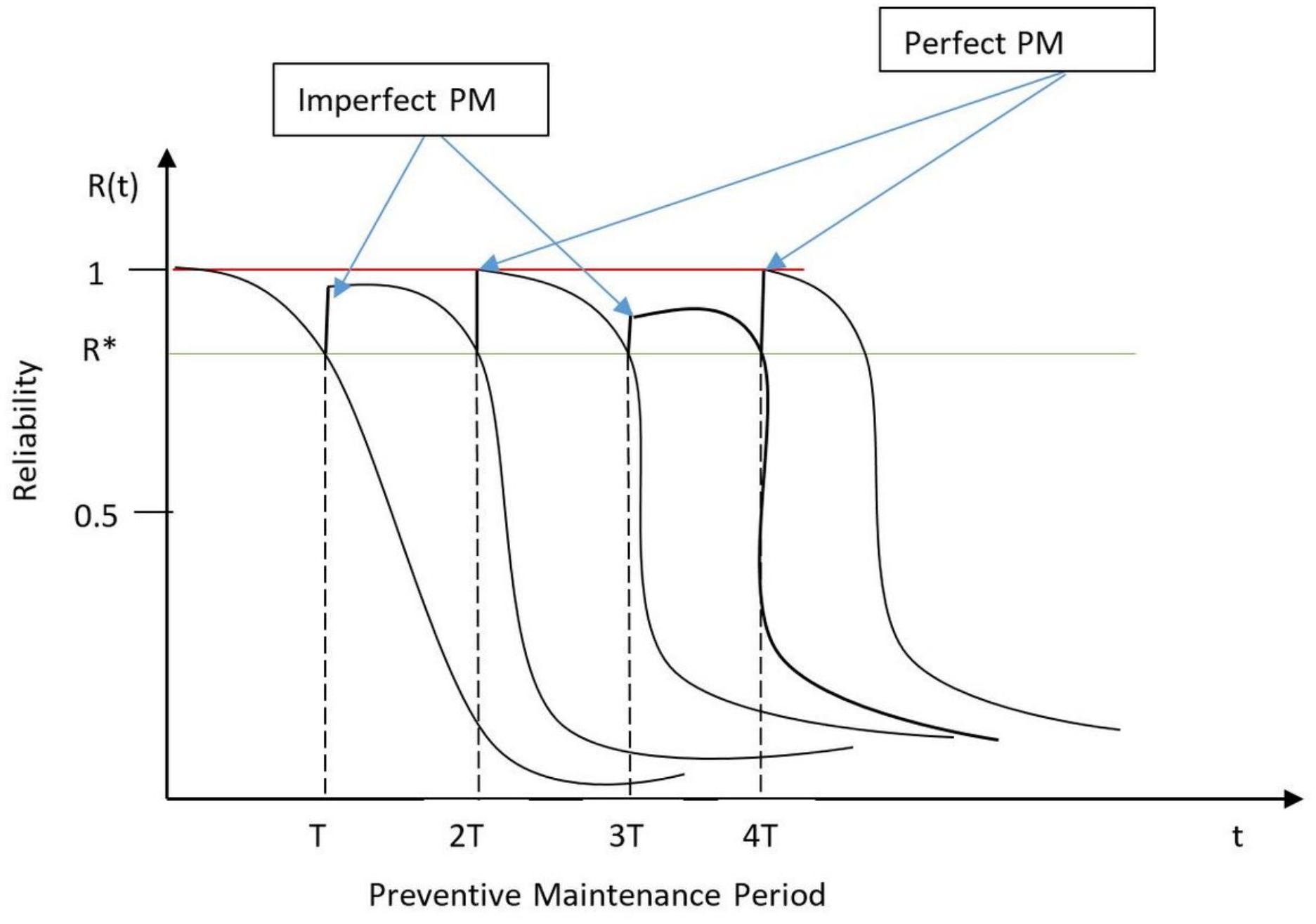

Figure 2

Evolution of the reliability of a system 


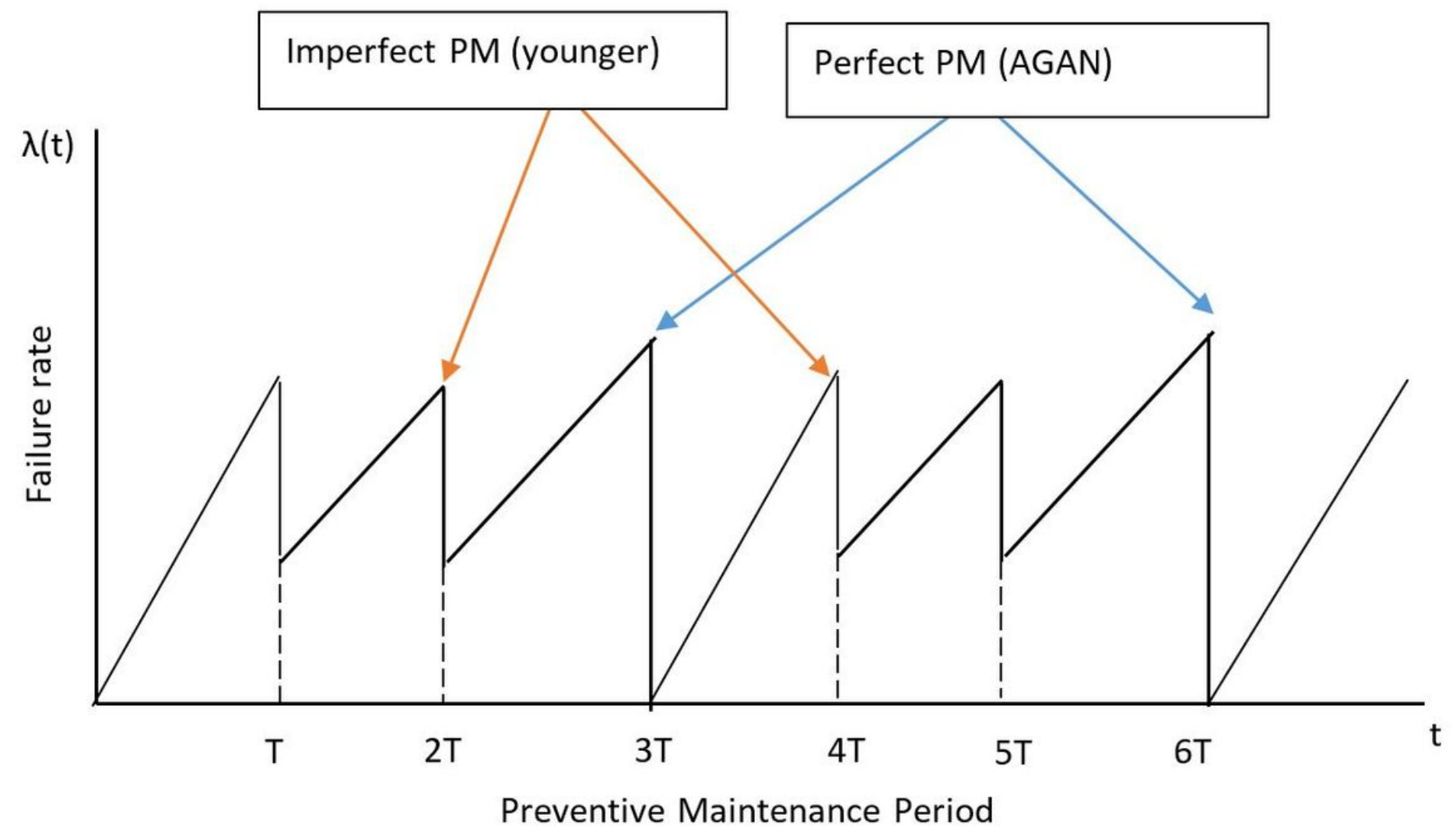

Figure 3

failure rate illustration during preventive maintenance actions 
$Z_{1}:$ Temperature

$$
\begin{array}{rrrrrr}
<-2 & <3.4 & <8.8 & <14.2 & <19.6 \\
0 & 1 & 2 & 3 & 4 & 5
\end{array}
$$

$Z_{2}:$ Irradiance

$$
\begin{array}{cccccc}
<120 & <186 & <252 & <318 & <384 & \\
0 & 1 & 2 & 3 & 4 & 5
\end{array}
$$

$Z_{3}:$ Humidity

$$
\begin{array}{rrrrrr}
<42 & <45.6 & <49.2 & <52.8 & <56.4 & \\
0 & 1 & 2 & 3 & 4 & 5
\end{array}
$$

$Z_{4}$ : Pression

$$
\begin{array}{cccccc}
<808 & <810.4 & <812.8 & <815.2 & <817.6 \\
0 & 1 & 2 & 3 & 4 & 5
\end{array}
$$

Figure 4

Criticality coefficient of the weather elements 


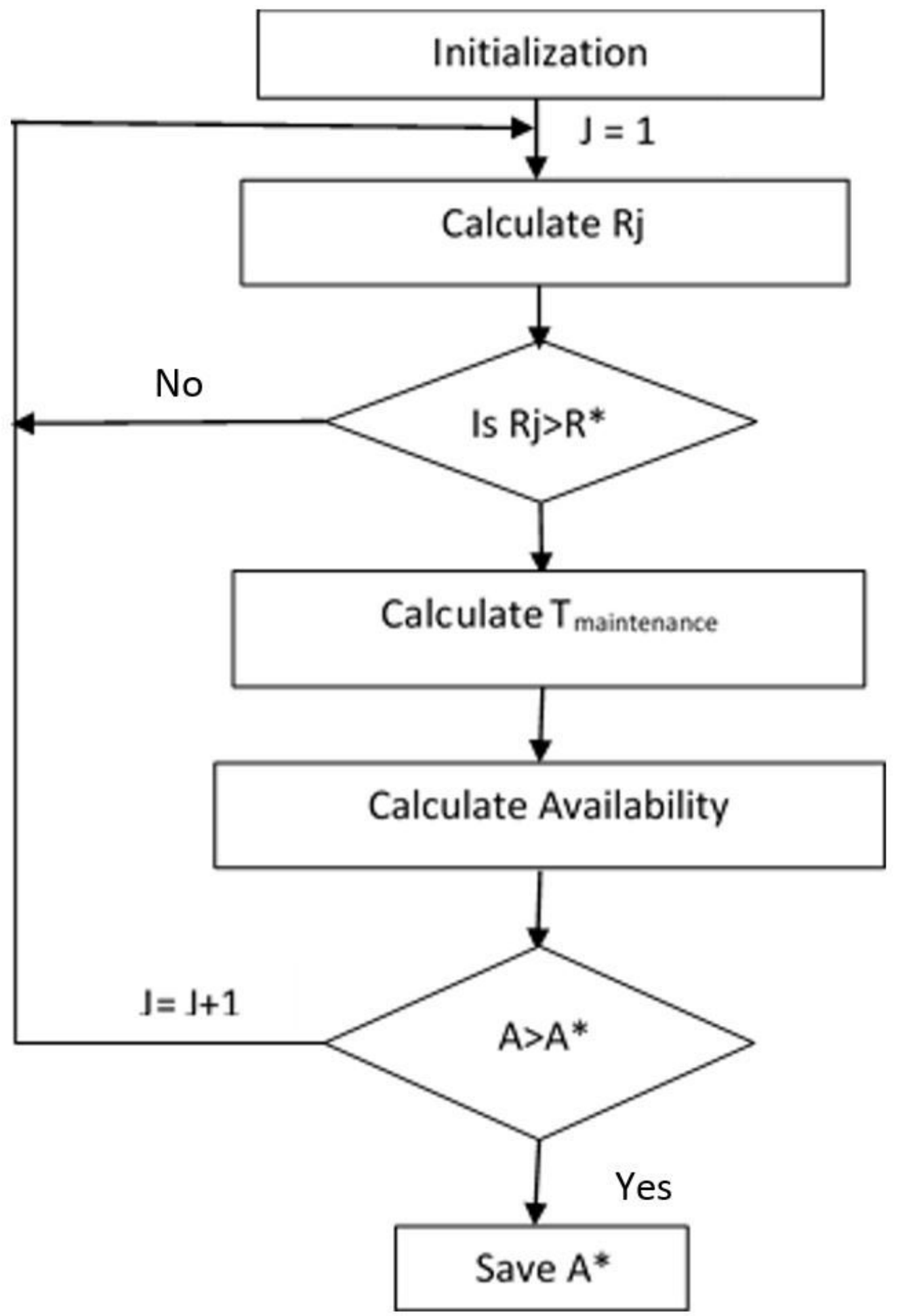

Figure 5

Algorithm flow chart 


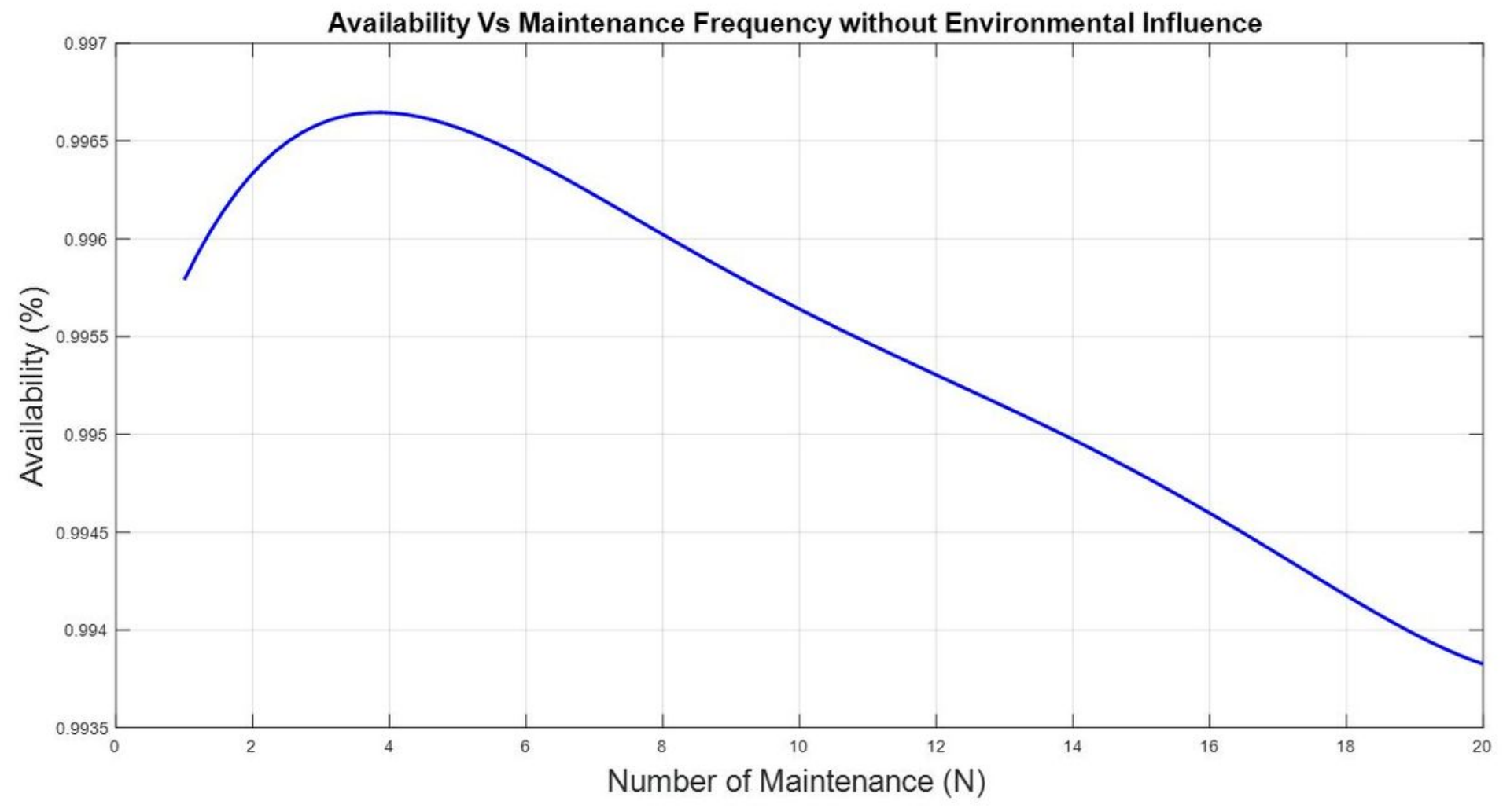

Figure 6

Availability for the system under the nominal environmental condition

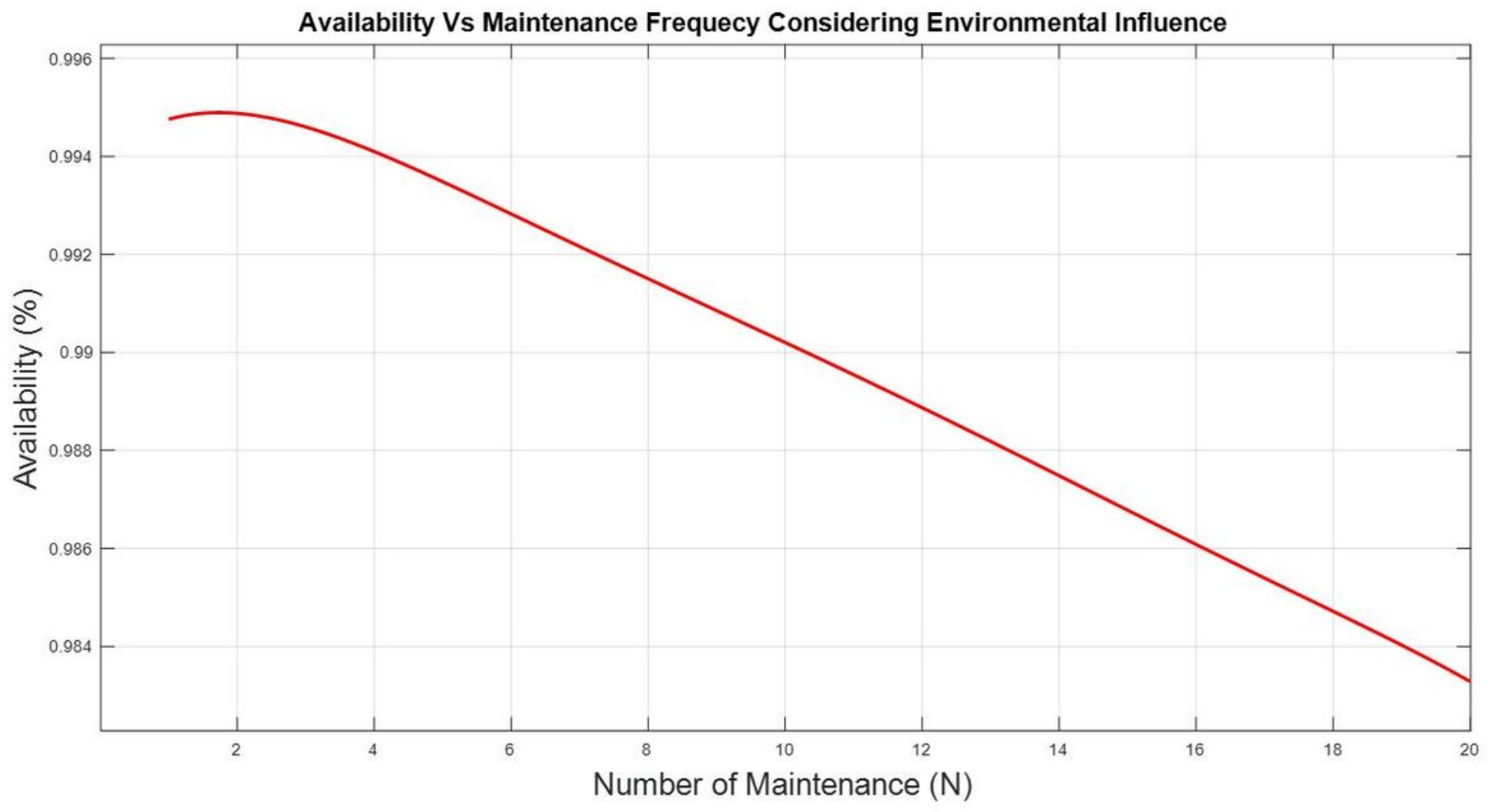

Figure 7 
Availability for the system under the influence of the environmental condition

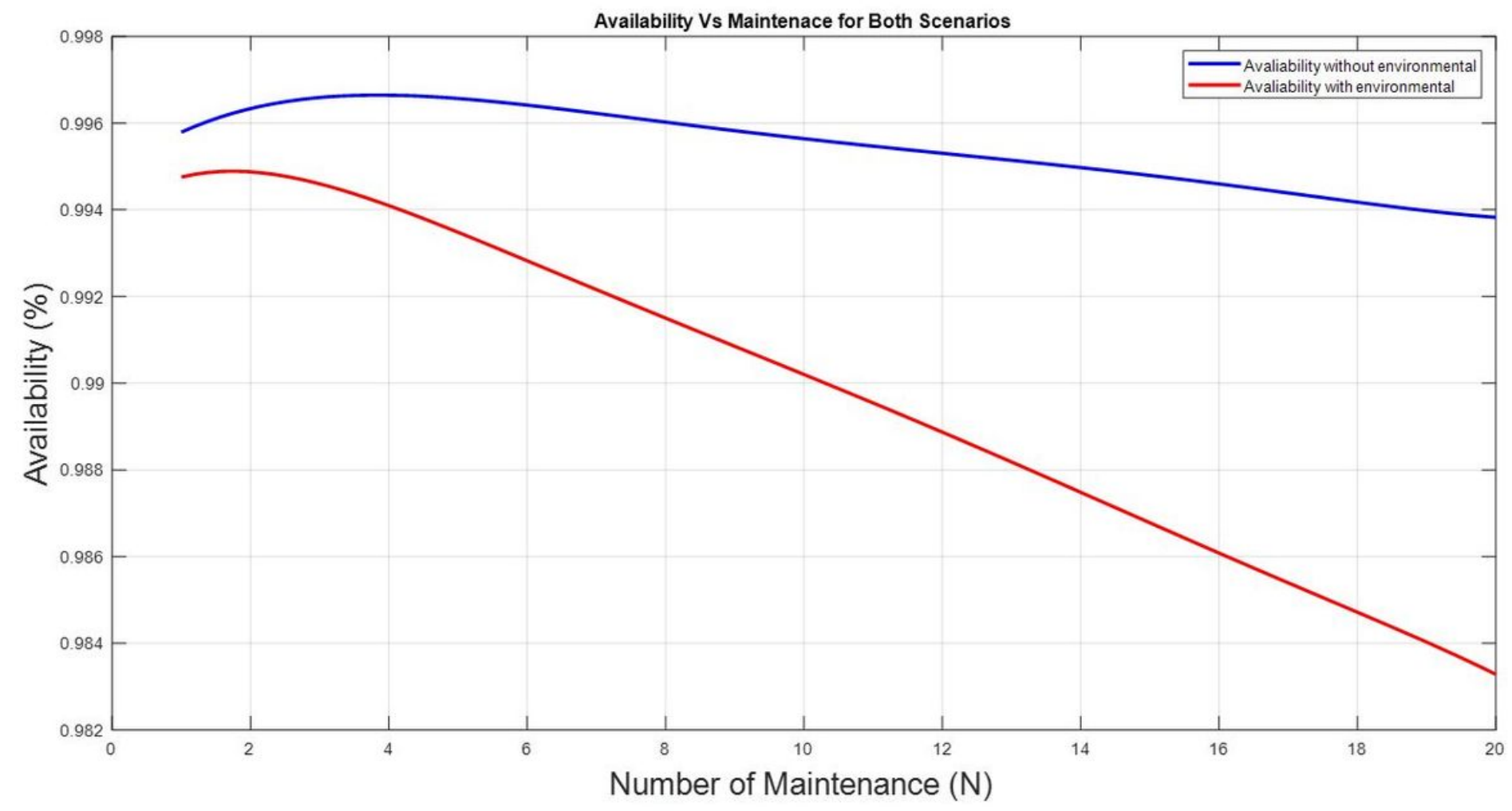

Figure 8

Availability for the system comparing the 2 scenarios. 